\title{
A Review on Modifications of Amniotic Membrane for Biomedical Applications
}

\author{
Fatemeh Dadkhah Tehrani ${ }^{1}$, Arezoo Firouzeh ${ }^{1}$, Iman Shabani ${ }^{1 *}$ and Azadeh Shabani2* \\ ${ }^{1}$ Cell Engineering and Bio-microsystems Laboratory, Biomedical Engineering Faculty, Amirkabir University of Technology, \\ Tehran, Iran, ${ }^{2}$ Preventative Gynecology Research Center, Department of Gynecology and Obstetrics, School of Medicine, \\ Shahid Beheshti University of Medical Sciences, Tehran, Iran
}

The amniotic membrane (AM) is the innermost layer of the fetal placenta, which surrounds and protects the fetus. Its unique structure, in addition to its physical and biological properties, makes it a useful substance in many applications related to regenerative medicine. The use of this fantastic substance with a century-old history has produced remarkable results in vivo, in vitro, and even in clinical studies. While the intact or preserved AM is widely used for these purposes, the addition of further modifications to AM can be considered as a relatively new subject in its applications. These modifications are applied to improve AM properties, ease of handling, and durability. Here, we will discuss the cases in which AM has undergone additional modifications besides the required processes for sterilization and preservation. In this article, we have categorized these modifications and discussed their applications and results.

Keywords: amniotic membrane, composites, hydrogel, tissue engineering, regenerative medicine

Abbreviations: ADA, alginate dialdehyde; ADA/REDV-AM, ADSCs: human adipose tissue-derived mesenchymal stromal cells; AM, amniotic membrane; AME, AM extract; AMEED, AME eye drop; AMSCs, amniotic membrane mesenchymal stromal cells; AMT, AM transplantation; ASA, acetylsalicylic acid; ASE, AM stromal extract; AT-MSCs, adipose tissue-derived mesenchymal stromal cells; AV, aloe vera; AlgSr/PAM, polyacrylamide-alginate; BAC, benzalkonium chloride; BAECs, bovine aortic endothelial cells; BAMCSM, bovine AM-chitosan membrane bFGF, basic fibroblast growth factor; CAM, chick chorioallantoic membrane; CBMSCs, cord blood-derived mesenchymal stromal cells; C/CS, collagen-chondroitin sulfate; CDAM, completely dried AM; CG, collagen-glycosaminoglycan; CM, chorion membrane; CME, CM extract; CS, chondroitin sulfate; dAM, decellularized amniotic membrane; dBAM, decellularized bovine AM; dAP, decellularized amniotic particles; DOX, doxorubicin; EDC/NHS, $N$-(3-dimethylaminopropyl)- $N$-ethylcarbodiimide/ $N$-hydroxysuccinimide; EDTA, ethylenediaminetetraacetic acid; EGF, endothelial growth factor; EPDC, human epicardial derived cells; FBS, fetal bovine serum; FG, fibrin glue; GelMA, methacrylated gelatin; HA, hyaluronic acid; HaCaT, human keratinocyte cell line; HASMC, human aortic smooth muscle cell; hcECM, human cardiac ECM; hCE, human corneal epithelial; hCECs, human corneal epithelial cells; hCF, human cardiac fibroblasts; HEK, human embryonic kidney 293 cell; HFF1, human fibroblast cell line; HGF, hepatocyte growth factor; HL1, murine cardiomyocyte-like cells; HUCBMSCs, human umbilical cord mesenchymal stromal cells; HUVEC, human umbilical vein endothelial cell; IL, interleukin; KGF, keratinocyte growth factor; LSC, limbal stem cell; ME, middle ear; MenSCs, menstrual blood-derived stem cells; MIF, migration inhibitory factor; mRNA, messenger RNA; NTHi, non-typeable Haemophilus influenza; NF, normal fibroblast; NOS, nitric oxide synthase; OM, otitis media; PAAc, poly(acrylic acid); pAM, particulated AM; pASC, porcine adipose-derived stem cells; PBMCs, peripheral blood mononuclear cells; PCL, poly( $\varepsilon$-caprolactone); PDAM, partially dried AM; PDGF, platelet-derived growth factor; PEG, polyethylene glycol; PEGDGE, poly(ethylene glycol) diglycidyl ether; PGE2, prostaglandin E2; PLA, poly(lactic acid); PLLA, poly(L-lactic acid); PLGA, poly(D,L-lactide-co-glycolide); PLGC, poly-(lactide-co-glycolide-co-caprolactone); PLCL, poly(Llactide-co- $\varepsilon$-caprolactone); PMSCs, placenta-derived mesenchymal stromal cells; PP, polypropylene; PSIS, porcine small intestinal submucosa; PVA, polyvinyl alcohol; RBC, red blood cell; REDV, arginine-glutamic acid-aspartic acid-valine; ROS, reactive oxygen species; SDS, sodium dodecyl sulfate; SMC, smooth muscle cell; SS, stainless steel; t-BOOH, tertiary butyl hydroperoxide; TE, tissue engineering; TGF- $\beta$, transforming growth factor beta; TIMP, tissue inhibitors of metalloproteinases; TNF- $\alpha$, tumor necrosis factor alpha; UF, ulcer fibroblast; UV, ultraviolet; VEGF, vascular endothelial growth factor.

Front Bioeng. Biotechnol

doi: 10.3389/fbioe.2020.606982 


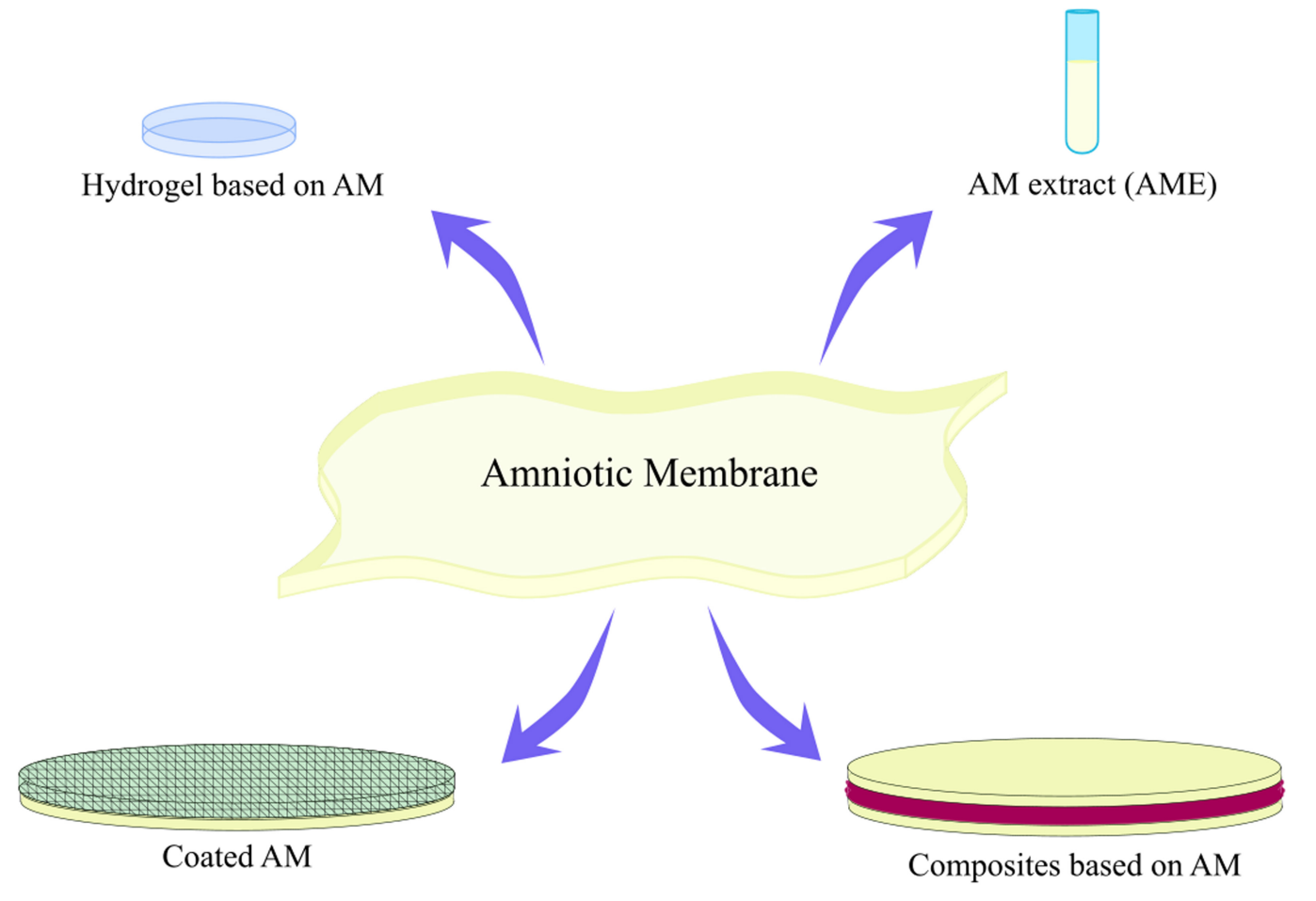

\section{INTRODUCTION}

In the modern world, there are many incidents such as trauma or congenital or genetic disorders that can induce tissue damage or dysfunction. The body's primary response to injury is to repair itself and maintain homeostasis for survival. This process, which is also known as tissue recovery, involves inflammation, cell proliferation, and tissue regeneration, which are all affected by cells and their microenvironment (Norouzi et al., 2015a). When an extensive injury has occurred, or functional recovery is not achieved, medical intervention is inevitable (Lewandrowski et al., 2002). One approach in these medical interventions is to replace the damaged tissue with an acceptable substitute. Depending on the type of the tissue and injury, this replacement could have a natural background such as autografts, allografts, and xenografts or could be a synthetic structure like a permanent implant. However, each of these structures is accompanied by its challenges. Tissue engineering (TE) is an alternative and promising strategy that can eliminate these limitations. Basically, in TE, cells are seeded on a scaffold, which provides temporal 3-dimensional (3D) support for cellular content and regulates their growth (Norouzi et al., 2015b). Over time, this scaffold is degraded and replaced by natural tissue. However, the utilization of any biological substitute in order to maintain, enhance, or restore tissue function is also under the scope of TE (Sharma et al., 2019). Various natural structures have the required therapeutic potential to be used as a tissue-engineered structure. Among them are the inner body membranes. Membranes actually consist of thin layers of cells or tissues that envelope the body, its internal organs, and cavities (Inci et al., 2020). Amniotic membrane (AM), Mesentery, omentum, pericardium, peritoneum, and pleura are all examples of these membranes with therapeutic applications (Inci et al., 2020). AM which is the innermost layer of the fetal membrane is a useful material with many applications in different fields of TE and regenerative medicine (Lacorzana, 2020). The application of AM has been reviewed in many articles. The most recent published reviews have focused on AM application in ophthalmology (Ehredt et al., 2019; Lacorzana, 2020), bonerelated surgeries (Horn et al., 2019; Puyana et al., 2019), skin burn (Hossain et al., 2020), and skin graft (Liu et al., 2018; Liang et al., 2019). In all of these articles, the application of unmodified AM has been studied. However, as its mechanical or biological properties were not efficient enough for some studies, some authors have employed different methods to enhance its features. For instance, attaching an electrospun layer on AM (Fard et al., 2018) or even electrospinning on AM (Mandal et al., 2017; Gholipourmalekabadi et al., 2018a,b; Arasteh et al., 2020), coating an additional layer on AM (Singh et al., 2008; Murphy et al., 2019), or utilization of AM extract (AME) in the form of hydrogel (Tseng, 2016) or eye drops (Mamede and Botelho, 2015) are all considered as a modification on AM. In this article, we have reviewed different kinds of AM modifications, both in intact and decellularized form (dAM) and their applications in the medical field. In the following sections, we have first introduced AM structure and function and, after that, reviewed composite structures based on AM, AME, and hydrogels based on AM. 


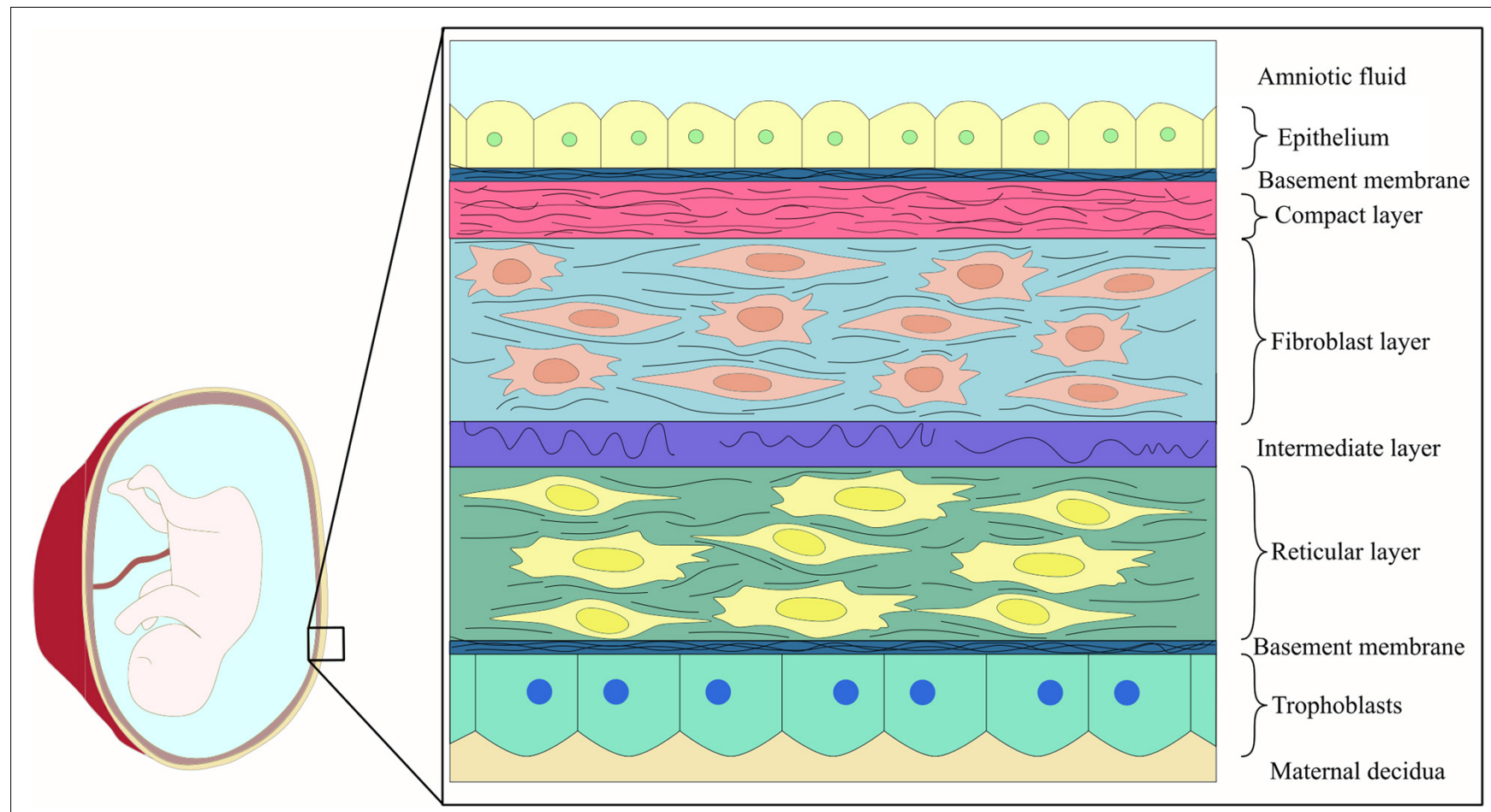

FIGURE 1 | Schematic representation of fetal membrane structure.

\section{AMNIOTIC MEMBRANE STRUCTURE, FEATURES, AND APPLICATIONS}

The chorioamniotic membrane is a thin layer wrapping the developing fetus and forming the amniotic cavity (Aziz et al., 2017). It consists of two layers: chorion and amnion. The outer layer (chorion) is in contact with the mother's cells and separated from the inner layer (amnion) by a jellylike matrix (Mamede et al., 2012; Islam et al., 2015). AM is composed of an epithelial layer, basement membrane, and three layers of stroma (a compact, a fibroblast, and a sponge layer) (Mamede et al., 2012; Figure 1). Although the primary function of this thin, transparent, resistant, and avascular membrane is to protect the fetus from unwanted substances, bacterial infection, and trauma during pregnancy (Mamede et al., 2012; Castellanos et al., 2017), it is not just a simple barrier. One of its other functions is to transport water and soluble substances to the fetus and provide growth factors and essential cytokines for it (Mamede et al., 2012; Islam et al., 2015).

The human AM has been widely used in TE and regenerative medicine not only due to its favorable biological and mechanical properties but also as its usage has low ethical problems (Mamede et al., 2012; Razzaghi et al., 2020). The first introduction of $\mathrm{AM}$ to the medical world was attributed to its similarity to human skin when Davies introduced the use of the AM in 1910 as a skin transplant. Following that in 1913, Stern and Sabella utilized AM for the treatment of skin burns and superficial wounds (Islam et al., 2015).
Since then, AM has been employed for numerous applications, including disorders associated with the urinary tract (Barski et al., 2017; Fénelon et al., 2018), oral cavity (Anisuzzaman et al., 2018; Farhadihosseinabadi et al., 2018), skin (Orman et al., 2018), stomach (Iravani et al., 2020), larynx (Turchan et al., 2018), head and neck (Şapte et al., 2017; Jorge et al., 2018), ocular surface (Gheorghe et al., 2016; Nassif et al., 2016), pelvic and abdominal surgery (Lau et al., 2020), and artificial vaginal reconstruction (Mao et al., 2016; Figure 2). All of these applications are the result of the interesting features of AM (Table 1). For instance, its antimicrobial characteristic has made it a suitable option for postsurgery applications in wound healing (Tandel et al., 2018), burn injuries (Mohan et al., 2017), dental injuries (Tabatabaei et al., 2017), and ophthalmology (King et al., 2007) as bacterial infection and biofilm growth are common in these sites (Attinger and Wolcott, 2012; Chen et al., 2012; Mamede et al., 2012). On the other hand, AM's mechanical properties are a subject of controversy. In some studies, its mechanical features are desirable, while in others it should be modified. This disagreement can be explained with the inherited variability in AM properties, which is necessary for its function, as well as the influence of preparatory methods on AM features (Chuck et al., 2004; Litwiniuk et al., 2018).

The type of delivery and the region from which the AM has been extracted are the two main factors affecting AM properties (Gremare et al., 2019). Although AM contains biologically active factors such as EGF, TGF- $\beta$, and TIMP-1, in addition to structural proteins, their distribution and concentration differ 


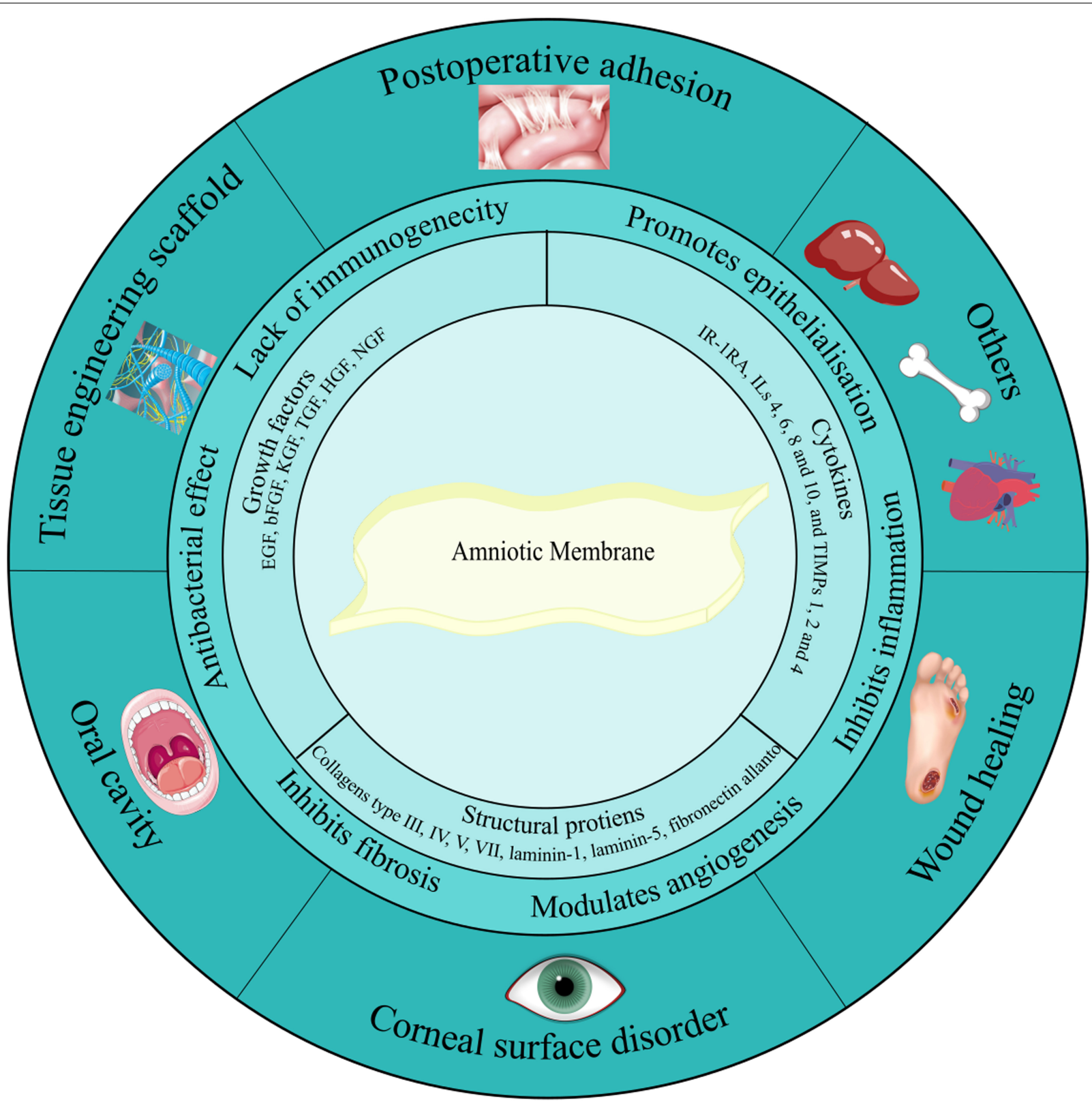

FIGURE 2 | Amniotic membrane components, characteristics, and applications. Amniotic membrane is rich in growth factors, cytokines, and structural proteins. These biological factors have given AM its unique features such as antibacterial effect, anti-inflammatory activity, anti-scarring, and anti-fibrosis potential. Due to these suitable features, nowadays AM is widely utilized as a therapeutic option in the treatment of various diseases related to the urinary tract, oral cavity, skin, stomach, larynx, head and neck, ocular surface, pelvic, and abdominal surgery. Additionally, it has been used as a natural scaffold in TE.

from one area to another. For instance, it has been proven that to ease fetal membrane rupture through delivery, AM has a weak zone overlying the cervix (Litwiniuk et al., 2017). Overall, in the case of physiological delivery-derived AMs, the placental portion has a more stimulatory influence on fibroblast and keratinocyte cell lines as it is rich in EGF and TGF- $\beta$; hence, it supports chronic wound healing (Brown et al., 1989; Ogawa et al., 2004; Gicquel et al., 2009). On the other hand, the cervical area of AM assessed from cesarean delivery, which has a low level of TGF- $\beta$, is more suitable for ophthalmologic applications (Brown et al., 1989; Kane et al., 1991). TGF- $\beta$ is highly essential during all phases of wound healing, but its overexpression, especially during eye surgery, can cause fibrosis and hypertrophic scar formation, which in the case of corneal damage may lead to a subsequent loss of corneal transparency (Branton and Kopp, 1999; Papakonstantinou et al., 2003; Fairbairn et al., 2014; Torricelli et al., 2016). In the case of mechanical properties, according to a recent study, placental $\mathrm{AM}$ is much stronger and stretchable than peripheral AM by an average of 82 and $19 \%$, respectively. 
TABLE 1 | Intact amniotic membrane biological and physical characteristics.

Amniotic membrane Contributing factors References
features

\section{Biological properties}

- Anti-inflammatory effect
Trapping inflammatory cells and driving them to apoptosis through its pro-apoptotic agents; production of anti-inflammatory factors by its epithelial cells; suppression the pro-inflammatory cytokines such as interleukin 1 alpha and 1 beta; production of MMP's inhibitors; expression of migration inhibitory factor (MIF); expression of anti-inflammatory cytokines such as IL-1 receptor antagonist; secretion of anti-inflammatory factors such as PGE2, TGF- $\beta$, HGF, TNF- $\alpha$, and MIF from mesenchymal and epithelial cells of AM

- Antibacterial and antiviral effect

- Low antigenicity and non-immunogenicity

- Anti-scarring and anti-adhesive effect in wound healing

- Angiogenesis and anti-angiogenesis properties (surface dependent)

- An anticancer agent with low tumorigenicity

- Promotion of epithelialization

- Pain reliever

- Support cell adhesion and growth

Mechanical prop

- Direct tensile mechanical properties
Expression of natural antibacterial molecules such as $\beta$-defensins, elafin, and cystatin E; adhesion to wound surface and to act as a barrier against bacterial infiltration

Lack of human leukocyte antigens A, B, C, and DR antigens, or $\beta 2$-microglobulin on the surface of AM epithelial cells; absence of vessels, lymph, and nerves, in its structure Reduction of proteases activity due to the secretion of tissue inhibitors of metalloproteinases (TIMPs); the decreased activity of fibroblasts through downregulation of TGF- $\beta$ with AM hyaluronic acid content

Angiogenesis properties: secretion of VEGF, IL-8, angiogenin, interferon- $\gamma$, IL-6, bFGF, EGF, and PDGF by AM mesenchymal cells

Anti-angiogenesis properties: secretion of IL-1, IL-2 receptor antagonist, IL-10, endostatin, TIMP-1, -2, -3, and -4, thrombospondin, and heparin sulfate proteoglycan by AM epithelial cells

Secretion of pro-apoptotic agents; secretion of IL-1, IL-2 receptor antagonist, IL-10, and endostatin which all inhibit tumor growth

Secretion of growth factors such as EGF, KGF, and HGF

Its hyaluronic acid content and proteins such as fibronectin, laminin, collagens, and proteoglycans act as a ligand for integrin receptors

\section{(intact AM)}

Placental:

Force before rupture: $1.2 \pm 0.2 \mathrm{~N}$

Strain at break: $19 \% \pm 3 \% \mathrm{~N}$

Peripheral:

Force before rupture: $0.68 \pm 0.08 \mathrm{~N}$

Strain at break: $16 \% \pm 1 \% \mathrm{~N}$
Mamede et al., 2012; Islam et al., 2015; Rocha and Baptista, 2015; llic et al., 2016

\author{
Mamede et al., 2012; Islam et al., 2015; \\ Castellanos et al., 2017; Milan et al., 2020 \\ Mamede et al., 2012; Chopra and Thomas, \\ 2013; Castellanos et al., 2017 \\ Mamede et al., 2012; Castellanos et al., \\ 2017
}

Islam et al., 2015; Ilic et al., 2016

Islam et al., 2015; Jafari et al., 2020

Mamede et al., 2012; Islam et al., 2015; Ilic et al., 2016; Castellanos et al., 2017

Mamede et al., 2012

llic et al., 2016

Litwiniuk et al., 2017
- Young's modulus
- Tensile strength
2.29-3.6 MPa
$5.475 \pm 0.135 \mathrm{MPa}$
- Elastic modulus

Niknejad et al., 2008

Cai et al., 2015; Ramesh et al., 2017
Aside from delivery mode, AM processing has a direct effect on its features. AM properties can be tailored only by changing the processing method (Aziz et al., 2017). In general, for AM clinical applications or its preservation in tissue banks, it is crucial to perform donor screening and selection, procure the membrane, wash it, and perform additional processing steps. It is common to treat the AM chemically or with antibiotic substrates, preserve, sterilize, package, and store it (Mamede et al., 2012). The reason for epithelial layer removal, AM sterilization, and its preservation are, respectively, to reduce graft rejection, minimize the risk of disease transmission, and store it more quickly for a more extended period (Gholipourmalekabadi et al., 2019a; Khosravimelal et al., 2020). Although AM-derived cells do not express immunogenic molecules, it has been reported that fresh AM can cause some inflammatory responses (Gholipourmalekabadi et al., 2019a); thus, it may be a better choice for some experiments to remove the cellular content of AM. There are different agents for AM decellularization, such as sodium dodecyl sulfate (SDS), urea, EDTA, and trypsin (Ilic et al., 2016). AM can be stored in a fresh, cryopreserved, or dried form. It can become cryopreserved with glycerol or DMSO and dried by freeze-drying, air, or oven-drying (Mamede et al., 2012); however, studies have shown that biological, morphological, and physical properties remain more intact with freeze-drying and storage in glycerol (Lacorzana, 2020).

Although all of the mentioned factors influence AM features, it is safe to say that AM in all forms (intact, dried, decellularized, and frozen) has unique properties suitable for many applications (Liu et al., 2018; Ehredt et al., 2019; Horn et al., 2019; Liang et al., 2019; Puyana et al., 2019; Hossain et al., 2020). Moreover, in some cases AM has been added to another material to improve its biological characteristics (Jiang et al., 2007). However, its mechanical and sometimes biological properties are sometimes not sufficient. To enhance these features, it is possible to apply $\mathrm{AM}$ in combination with another material. In the following sections, we have reviewed these modifications and categorized 
them into three main groups: composites based on AM, AM extract (AME), and hydrogels based on AM. The information given in each part is summarized in a table following that section.

\section{COMPOSITES BASED ON AMNIOTIC MEMBRANE}

As it was mentioned previously, AM's ECM is rich in structural proteins with a variety of biochemical cues and has been successfully utilized as a basement membrane substitute (Sekiyama et al., 2007). However, its inherent limitations, such as poor mechanical properties, short-term therapeutic efficiency, the difficulty of handling and suturing during surgeries, and inefficient adhesive properties, highlight the need for modifications (Cai et al., 2015). To overcome the limitations associated with AM, some authors considered the development of biocomposites based on AM by the addition of polymers, fibrin glue, or any other material to it. On the other hand, sometimes AM is utilized in composite form just to enhance the biological properties of another material. In this section, we have categorized these composites in three subgroups: coated AM, AM as a coating, and composites based on pulverized AM. Following this, we will discuss the advances in this field and summaries them in Table 2.

\section{Coated Amniotic Membrane}

The unique properties of the AM have encouraged researchers to use it for a variety of applications. In some cases, other biological or non-biological components are coated on the AM to improve its properties and performance. The secondary agent can be in the form of particles, gels or biological glues, and a polymeric or an electrospun layer. In some studies, the secondary agent has been only placed on the AM surface, while in others, it has been immobilized on the surface of AM through a chemical reaction.

\section{Amniotic Membrane Coated With Particles}

Biological or chemical particles can be coated on the membrane structure through various processes such as peptide self-assembly (Singh et al., 2008) and deposition (Murphy et al., 2019). These modified constructs have mainly been utilized to improve the antimicrobial effect of AM (Singh et al., 2008; Murphy et al., 2019). For instance, in one study, Mandel et al. coated dAM with clavanin A, after it was modified with self-assembly, to prevent biofilm formation over the membrane. Based on their study, the A-coated dAM had better biocompatibility as well as lower cell attachment colonization and fungal colonization $(p<0.05)$ in comparison with the dAM. Moreover, it showed excellent physical, morphological, and antifungal characteristics, which made it suitable for ocular surface infection control (Singh et al., 2008). In another study, Singh et al. improved the antibacterial property of AM by silver deposition. In situ reduction was the method of choice for this deposition and resulted in the formation of a barrier against the penetration of bacteria. Additionally, this structure obtained a controlled release of moisture vapor and showed a great absorption capacity (Murphy et al., 2019).

\section{Amniotic Membrane Coated With Gels and Biological Glues}

Another approach to ameliorate AM properties in a composite form is to combine it with a gel or a biological glue. These composites are mainly designed to improve the adhesive and biological properties of AM. For instance, AM has been extensively utilized for ocular surface reinstruction; however, due to inefficient mechanical properties of fresh and dried AM, single-layer transplantation of AM has proven to be insufficient. Moreover, merely adding multiple layers of AM is not enough as they require excessive stitches to remain attached to each other and the surface of the eye (Brücher et al., 2020). However, by adding fibrin glue (FG) to this structure, it is possible to enhance the mechanical properties of AM (tensile strength: $0.727 \mathrm{MPa}$, strain at break: $24.130 \%$ ) while reducing the need for stitches. Moreover, FG-double layer AM improves the rate of epithelial healing (Cai et al., 2015). Fibrin glue has also been added to AM just to avoid sutures for binding AM to the ocular surface (Sekiyama et al., 2007). In another experiment, the effect of chitosan and/or halofuginone gel coating on AM to reduce tissue adhesion was studied by Washburn et al. (2010). They evaluated this effect on a rat uterine injury model and concluded that AM both as a single layer or coated with gel reduced moderate and severe tissue adhesion. Likewise, when AM was coated with halofuginone alone or in combination with chitosan, the percentage of adhesions declined.

To enhance the biological properties of AM, a novel composite patch based on dAM has been developed for cardiac TE (Becker et al., 2018). This structure was prepared by combining a hydrogel obtained from human cardiac ECM (hcECM) with dAM via the dry-coating procedure. According to the results of this study, coating dAM with hcECM modified the regenerative properties of the dAM so that it would be better suited for applications related to the heart. This composition did not alter the mechanical properties of the dAM, as they can affect cell behavior. Moreover, the tissue-specific protein composition of the myocardial ECM, which is essential for its biological activity as a lineage supporter and cytoprotector, remained intact. Overall, based on their results, this scaffold may be a potential platform for the epicardial delivery of cells and therapeutic agents as it has superior adhesion capacity, supports cell proliferation and viability, and modulates inflammatory responses.

\section{Amniotic Membrane Coated With a Layer}

The most widely used approach for enhancing AM properties is to utilize multilayered constructs of AM in combination with a polymeric layer, which can be constructed in a variety of ways. One strategy is to combine AM with an electrospun layer either by direct electrospinning the secondary material on the AM or conjugating the surface-activated nanofiber mesh on the AM (Figures 3A,B). Another method is to add a casted layer on top of AM. 
TABLE 2 | Summary of composites based on AM.

\begin{tabular}{|c|c|c|c|c|c|}
\hline Author, year & $\begin{array}{l}\text { Therapeutic } \\
\text { goal }\end{array}$ & $\begin{array}{l}\text { Experimental settings } \\
\text { (target tissue/cells) }\end{array}$ & $\begin{array}{l}\text { Secondary } \\
\text { biomaterial }\end{array}$ & Conclusion & References \\
\hline Uchino, 2006 & $\begin{array}{l}\text { Artificial cornea } \\
\text { scaffold }\end{array}$ & $\begin{array}{l}\text { In vitro } \\
\text { (rabbit corneal epithelium) }\end{array}$ & PVA & $\begin{array}{l}\text { PVA-AM is a biocompatible hybrid material } \\
\text { for keratoprosthesis }\end{array}$ & Uchino et al., 2007 \\
\hline Jiang, 2007 & $\begin{array}{l}\text { Intravascular } \\
\text { stent }\end{array}$ & - & SS stent & $\begin{array}{l}\text { AM is an excellent elastic material for stent } \\
\text { covering and has a good blood } \\
\text { compatibility }\end{array}$ & Jiang et al., 2007 \\
\hline Singh, 2008 & Burn dressing & - & Silver & $\begin{array}{l}\text { Deposition of silver particles on AM results } \\
\text { in the formation of an antibacterial barrier } \\
\text { with controlled release of moisture vapor } \\
\text { and a high absorption capacity }\end{array}$ & Murphy et al., 2019 \\
\hline Cai, 2015 & $\begin{array}{l}\text { Ocular surface } \\
\text { reconstruction }\end{array}$ & $\begin{array}{l}\text { In vivo } \\
\text { (rabbit) }\end{array}$ & $F G$ & $\begin{array}{l}\text { FG-double-layered AMT has excellent } \\
\text { stability and short operating time and } \\
\text { promotes a stable and rapid reconstruction } \\
\text { of the ocular surface }\end{array}$ & Cai et al., 2015 \\
\hline Hortensius, 2016 & $\begin{array}{l}\text { Tendon } \\
\text { regeneration }\end{array}$ & $\begin{array}{l}\text { In vitro } \\
\text { (equine tenocytes) }\end{array}$ & CG & $\begin{array}{l}\text { Incorporation of dAM into CG-based } \\
\text { scaffold results in a modified inflammatory } \\
\text { response of the target tissue }\end{array}$ & $\begin{array}{l}\text { Hortensius et al., } \\
2016\end{array}$ \\
\hline Najibpour, 2016 & $\begin{array}{l}\text { Abdominal } \\
\text { hernias }\end{array}$ & $\begin{array}{l}\text { In vivo } \\
\text { (Dutch white rabbits) }\end{array}$ & PP mesh & $\begin{array}{l}\text { Addition of AM to PP mesh results in less } \\
\text { adhesion and inflammation, higher } \\
\text { epithelialization, and wound healing } \\
\text { improvement }\end{array}$ & $\begin{array}{l}\text { Najibpour et al., } \\
2016\end{array}$ \\
\hline Hortensius, 2018 & $\begin{array}{l}\text { Tendon } \\
\text { regeneration }\end{array}$ & $\begin{array}{l}\text { In vitro } \\
\text { (MSC) }\end{array}$ & $\begin{array}{l}\text { Collagen } \\
\text { scaffold }\end{array}$ & $\begin{array}{l}\text { The addition of dAM to collagen-based } \\
\text { scaffolds as bulk incorporation or a } \\
\text { membrane wrap results in a biomaterial } \\
\text { with both a tendon-mimicking structure and } \\
\text { an immunomodulatory effect }\end{array}$ & $\begin{array}{l}\text { Hortensius et al., } \\
2018\end{array}$ \\
\hline Liu, 2018 & LSC deficiency & $\begin{array}{l}\text { In vitro } \\
\text { (primary rabbit LSCs and } \\
\text { bone-mouse marrow-derived } \\
\text { macrophages) }\end{array}$ & $\begin{array}{l}\text { Polymeric fiber } \\
\text { mesh }\end{array}$ & $\begin{array}{l}\text { The composite membrane based on } \\
\text { lyophilized dAM and nanofiber mesh offers } \\
\text { superior mechanical features as well as } \\
\text { necessary biochemical cues for LSC } \\
\text { attachment, growth, and maintenance }\end{array}$ & Fard et al., 2018 \\
\hline Rashid, 2018 & $\begin{array}{l}\text { Abdominal wall } \\
\text { hernias }\end{array}$ & $\begin{array}{l}\text { In vivo } \\
\text { (Wistar albino rats) }\end{array}$ & PEG+PP mesh & $\begin{array}{l}\text { Coverage of PP mesh with BAM and } 5 \% \\
\text { PEG results in the lowest adhesion } \\
\text { percentage }\end{array}$ & Rashid et al., 2018 \\
\hline Soylu, 2018 & $\begin{array}{l}\text { Abdominal wall } \\
\text { defect }\end{array}$ & $\begin{array}{l}\text { In vivo } \\
\text { (Wistar albino rats) }\end{array}$ & PP mesh & $\begin{array}{l}\text { Addition of AM to PP mesh results in less } \\
\text { intra-abdominal adhesions, less } \\
\text { inflammation, and higher epithelialization }\end{array}$ & Soylu et al., 2018 \\
\hline Aslani, 2019 & $\begin{array}{l}\text { Vascular tissue } \\
\text { engineering }\end{array}$ & $\begin{array}{l}\text { In vitro } \\
\text { (HUVEC and MSC) }\end{array}$ & PLLA-ASA & $\begin{array}{l}\text { AM-coated ASA-loaded aligned } \\
\text { electrospun scaffold supports endothelial } \\
\text { differentiation and provides superior } \\
\text { biocompatibility with appropriate signals } \\
\text { needed by EC }\end{array}$ & Aslani et al., 2019 \\
\hline
\end{tabular}


TABLE 2 | Continued

\begin{tabular}{|c|c|c|c|c|c|}
\hline Author, year & $\begin{array}{l}\text { Therapeutic } \\
\text { goal }\end{array}$ & $\begin{array}{l}\text { Experimental settings } \\
\text { (target tissue/cells) }\end{array}$ & $\begin{array}{l}\text { Secondary } \\
\text { biomaterial }\end{array}$ & Conclusion & References \\
\hline $\begin{array}{l}\text { Gholipourmalekabadi, } \\
2019\end{array}$ & $\begin{array}{l}\text { Modulation of } \\
\text { hypertrophic scar } \\
\text { formation }\end{array}$ & $\begin{array}{l}\text { In vitro and in vivo (human } \\
\text { ADSCs, rabbit ear model) }\end{array}$ & Silk fibroin & $\begin{array}{l}\text { AM/silk minimizes the post-injury } \\
\text { hypertrophic scar formation through } \\
\text { decreasing the collagen deposition and } \\
\text { increasing MMP1 expression and } \\
\text { deposition }\end{array}$ & $\begin{array}{l}\text { Gholipourmalekabadi } \\
\text { et al., 2019b }\end{array}$ \\
\hline Ramakrishnan, 2019 & Wound healing & $\begin{array}{l}\text { In vitro } \\
\text { (dermal fibroblasts) }\end{array}$ & $\begin{array}{l}\text { PLGC+PEG+ } \\
\text { SNP+fibrin }\end{array}$ & $\begin{array}{l}\text { Combination of AM-F-PLGC-SNP can be } \\
\text { advantageous not only for wound coverage } \\
\text { but also for skin tissue regeneration }\end{array}$ & $\begin{array}{l}\text { Ramakrishnan et al., } \\
2019\end{array}$ \\
\hline Zhang, 2019 & Oral defects & $\begin{array}{l}\text { In vitro and in vivo } \\
\text { (human fibroblasts, CAM assay, } \\
\text { New Zealand white rabbits) }\end{array}$ & GelMA & $\begin{array}{l}\text { Composition of GelMA and particulated AM } \\
\text { resulted in an easy to synthesize, store, and } \\
\text { handle substrate suitable for the treatment } \\
\text { of oral mucosal defects }\end{array}$ & Zhang et al., 2019 \\
\hline Zhou, 2019 & $\begin{array}{l}\text { Corneal epithelial } \\
\text { defect }\end{array}$ & $\begin{array}{l}\text { In vivo } \\
\text { (rabbit) }\end{array}$ & PCL & $\begin{array}{l}\text { PCL-dAM composite has pro-regenerative } \\
\text { and immunomodulatory properties of dAM } \\
\text { and with a lower degeneration rate }\end{array}$ & Zhou et al., 2019 \\
\hline Adamowicz, 2020 & $\begin{array}{l}\text { TE of the urinary } \\
\text { bladder }\end{array}$ & $\begin{array}{l}\text { In vitro } \\
\text { (SMC derived from porcine } \\
\text { detrusor and porcine UC) }\end{array}$ & $\begin{array}{l}\text { Graphene } \\
\text { layers }\end{array}$ & $\begin{array}{l}\text { Intact AM covered with solid graphene } \\
\text { layers has the potential to obtain electrical } \\
\text { stimulation for smooth muscle layer }\end{array}$ & $\begin{array}{l}\text { Adamowicz et al., } \\
2020\end{array}$ \\
\hline Akyürek, 2020 & $\begin{array}{l}\text { Prevent capsule } \\
\text { contraction } \\
\text { in Silicone breast } \\
\text { implants }\end{array}$ & $\begin{array}{l}\text { In vivo } \\
\text { (Wistar rats) }\end{array}$ & Silicon & $\begin{array}{l}\text { Coating silicone implants with AM reduces } \\
\text { capsule thickness in comparison with bare } \\
\text { silicon }\end{array}$ & Akyürek et al., 2020 \\
\hline Dewey, 2020 & Bone repair & $\begin{array}{l}\text { In vitro } \\
\text { (pASC) }\end{array}$ & $\begin{array}{l}\text { Collagen } \\
\text { scaffold }\end{array}$ & $\begin{array}{l}\text { Collagen-dAM composite scaffold is } \\
\text { potentially suitable for craniomaxillofacial } \\
\text { bone repair especially in the presence of } \\
\text { inflammation }\end{array}$ & Dewey et al., 2020 \\
\hline Yang, 2020 & Wound healing & $\begin{array}{l}\text { In vitro and in vivo } \\
\text { (human foreskin fibroblast cells } \\
\text { and mice) }\end{array}$ & Chitosan & $\begin{array}{l}\text { Double-layer membrane based on dBAM } \\
\text { and chitosan is a biocompatible structure } \\
\text { with potential benefits in healing } \\
\text { full-thickness diabetic patients }\end{array}$ & Yang et al., 2020 \\
\hline
\end{tabular}

Silk is one of the natural biomaterials that have been added to AM to improve its mechanical properties as well as degradation rate (Gholipourmalekabadi et al., 2018b). Silks' biocompatibility, non-cytotoxicity, low immunogenicity, ease of manipulation, low rate of biodegradability, and mechanical and structural superiority have paved the way for its extensive application in biomedical applications and wound healing (Mandal et al., 2017; Gholipourmalekabadi et al., 2018a,b, 2019b). Thus, in some cases, especially for skin regeneration, silk nanofibers were electrospun on dAM (Figure 3C; Mandal et al., 2017; Gholipourmalekabadi et al., 2018a,b; Arasteh et al., 2020). In addition to better maintenance of the $3 \mathrm{D}$ structure, these constructs supported cell adhesion (Gholipourmalekabadi et al., 2018b), keratinocyte differentiation (Gholipourmalekabadi et al., 2018a), and skin regeneration. Moreover, while they regulated inflammation (Mandal et al., 2017), no detectable cytotoxicity had been observed (Gholipourmalekabadi et al., 2018b). According to Gholipourmalekabadi et al. (2019b) AM/silk had the same effect on cell viability and cytotoxicity as simple AM in vitro. Additionally, they showed that AM/silk minimized the postinjury hypertrophic scar formation in the rabbit ear model in vivo as it decreased the collagen deposition while it increased MMP1 expression and deposition.

As was mentioned in the previous section, improving mechanical properties and regulating the degradation rate of
$\mathrm{AM}$ is necessary for its practical application in the treatment of ocular surface disorders. For instance, limbal stem cell (LSC) expansion is one of the most promising areas for AM applications, yet challenges have always accompanied it due to poor mechanical characteristics of AM (Serna-Ojeda et al., 2020). To overcome this challenge, Liu et al. developed another composite structure based on AM to enhance its tensile property and toughness. They evaluated its effect on the treatment of LSC deficiency and corneal injuries (Fard et al., 2018). This structure, which was based on dAM and a fiber mesh, combined the biochemical activity of dAM necessary for LSC adhesion, growth, and maintenance with a mechanically stable structure (Liu et al., 2018; Zhou et al., 2019). In this study, three polymers (PLA, PLGA, and PCL) underwent electrospinning to form three nanofiber meshes, and following that, each of them was grafted with PAAc chains. Based on Liu et al. findings, the composite membrane was easier to manipulate in comparison with fresh and freeze-dried AAM; retained dAM support of rabbit LSC attachment, proliferation, and maintenance; and regulated inflammatory response for 7 days and had anti-inflammatory properties. Based on their results, elastic modulus, strain to failure, ultimate tensile strength, toughness, and failure force with suture of all the composite scaffolds were much higher than dAM. However, the PCL fiber-dAM scaffold possessed more balanced mechanical properties for the application in LSC 
A

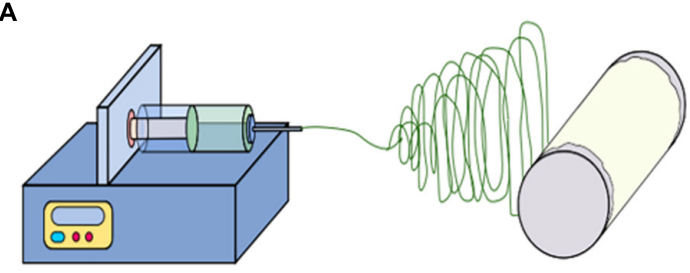

C
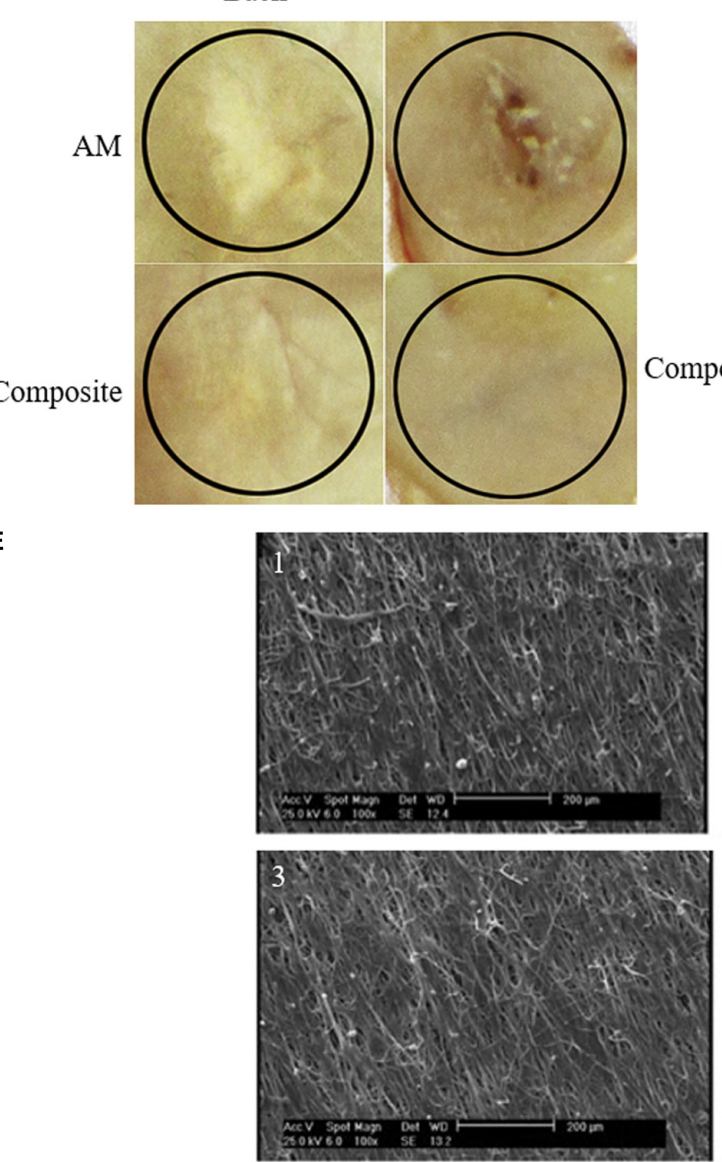

B

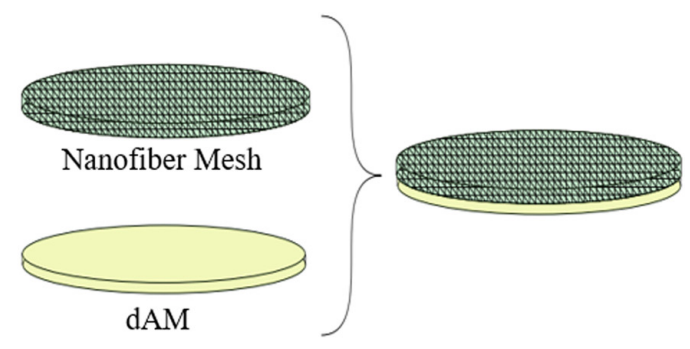

D

Week 1

Week 2
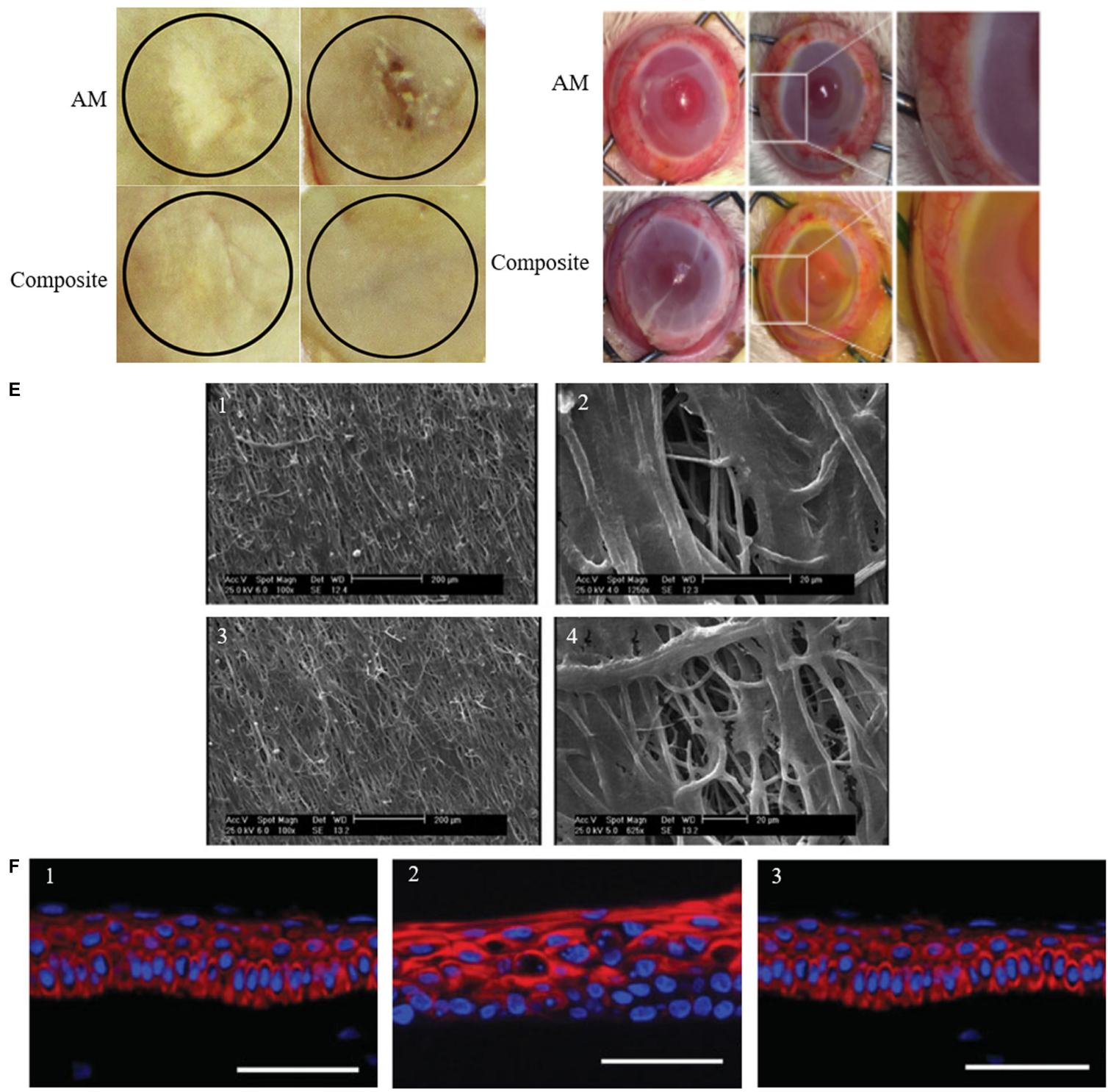

FIGURE 3 | (A) Schematic representation of direct electrospinning of secondary material on AM. (B) Conjugation of the surface-activated nanofiber mesh on the AM. (C) Gross healed wound areas after 30 days of wound healing from front and back views comparing AM and composite effect [reproduced with permission from Mandal et al., 2017. Copyright 2020 Elsevier]. (D) Maintenance of structural integrity, reduction of vascularization, and degradation after PCL-dAM composite transplantation in comparison with the AM-treated group for treating alkali-burn induced LSCD model [reproduced with permission from Zhou et al., 2019. Copyright 2019 Elsevier]. (E) Attachment and infiltration of Wharton's jelly-derived MSCs seeded on the PLLA scaffolds after 7 days in two different magnification. (1, 2) Aligned PLLA scaffold containing ASA. (3, 4) Aligned PLLA scaffold containing ASA and coated with AM lysate [reproduced with permission from Aslani et al., 2019. Copyright 2019 Wiley]. (F) Representative series of expression of corneal epithelium-specific keratin 3 (K3) in epithelial cells cultured on (1) PVA-AM, (2) PVA-collagen, and (3) normal rabbit cornea [reproduced with permission from Uchino et al., 2007. Copyright 2007 Wiley]. 
transplantation (Liu et al., 2018). In another study, Zhou et al. employed PCL-dAM composite to improve LSC expansion in the rabbit corneal epithelial defect model (Figure 3D). They have reported that this composite membrane maintained the pro-regenerative and immunomodulatory properties of dAM and, at the same time, reduced its degeneration rate by $40 \%$, which means it can provide lasting coverage in the defect site (Zhou et al., 2019).

Amniotic membrane has also been utilized in the field of urological TE due to its potential to support smooth muscle cell (SMC) regeneration and induce epithelialization (Sharifiaghdas et al., 2009; Adamowicz et al., 2012). Adamowicz et al. (2016) have developed a biocomposite material based on frozen AM and electrospun membranes for the regeneration of the bladder wall. This structure was constructed from a frozen AM sandwiched between two layers of electrospun poly(L-lactide-co-e-caprolactone) (PLCL). According to Adamowicz et al., PLCL layers not only improved the mechanical properties of AM but also promoted the cellularization of AM by the host's cells. Furthermore, based on their report, this biocomposite material induced the formation of a multilayered bladder wall similar to native bladder but stiffer (lower Young's modulus by nearly two folds) within 12 to 14 weeks.

Another strategy is to add silver nanoparticles as well as an electrospun layer, to the AM to improve its antibacterial effects. For example, in one study, Ramesh et al. (2017) electrospun a combination of umbilical cord collagen and green silver nanoparticles on cross-linked dAM to construct a hybrid biological nano-scaffold with long shelf-life for wound healing. The green silver nanoparticles, which were prepared with reducing silver nitrate by Curcumin, promoted scarless healing as silver modulates inflammatory response, and curcumin is a wound-healing agent. Their in vitro assessment showed that this scaffold was efficient for the differentiation of human cord blood-derived stromal cells (CBMSCs) to keratinocytes and skin fibroblasts. Also, they provided evidence that this dressing enhances the wound healing process (almost 100\% after 21 days - with the formation of hair follicles and sweat glands and epithelialization in some wounds) and minimizes scar formation in small animal models. According to their results, although the AM was superhydrophobic, the electrospun layer retained moisture. Additionally, this dressing, which had a superior tensile strength in comparison with native AM $(7.96 \pm 3.06 \mathrm{MPa})$, provided a sustained/controlled release of silver and needed fewer dressing changes (Ramesh et al., 2017).

In another study, Ramakrishnan et al. also added silver antibacterial properties to the composite structure based on AM and an electrospun layer with improved handling properties. Their proposed scaffold was prepared with electrospinning of the poly-(lactide-co-glycolide-co-caprolactone) (PLGC) terpolymer after it was incorporated with PEG-protected SNPs, on a layer of fibrin and AM (Ramakrishnan et al., 2019). This biodegradable combinatory scaffold with biological cues was used as a wound dressing for dermal regeneration. According to their results, the properties of this scaffold are superior to each component alone as it had the mechanical strength of
PLGC, suitable biological properties of AM, cellular stimulatory effect of fibrin, and antimicrobial property of SNPs. The tensile strength (3.62 $\pm 0.4 \mathrm{MPa})$, elongation $(10.6 \pm 4.6 \mathrm{MPa})$, modulus $(67.3 \pm 19.6 \mathrm{MPa})$, and swelling percentage of composite scaffold improved in comparison with AM. On the other hand, the addition of AM supported fibroblast attachment and growth on the PLGC-SNP scaffold for 14 days.

Another example of multilayered AM composite with an electrospun layer for improved biological properties has been developed for vascular TE. Engineering smalldiameter vascular graft is more challenging than large ones. While for large-diameter arteries, bio-stable and mechanically strong synthetic grafts have been developed and used successfully, small-diameter vessels require a more biocompatible vascular graft with precise structural, biophysical, and topographical design (Ravi and Chaikof, 2010; Aslani et al., 2019). To achieve this goal, Aslani et al. (2019) fabricated an electrospun poly(L-lactic acid) (PLLA) scaffold containing an anticoagulation agent (acetylsalicylic acid-ASA) and coated its surface with AM lysate prepared with the digestion of $\mathrm{AM}$ in an enzymatic solution made from $\mathrm{HCl}$ and pepsin, which is rich in basement membrane proteins and glycoproteins. The inner surface of their proposed scaffold supported endothelial differentiation, which is a natural anticoagulant. Among the fabricated scaffolds they have studied, aligned ASA-loaded AM lysate-coated scaffolds were the best option, which supported endothelial cell differentiation (Figure 3E). In this study, AM was utilized to improve the overall cytocompatibility of the scaffold for human umbilical vein endothelial cell (HUVEC) culture and endothelial differentiation of MSC.

In a new study, a wound dressing based on decellularized bovine AM (dBAM) and sponge-like chitosan membrane (BAMCSM) has been developed to accelerate diabetic wound healing (Yang et al., 2020). This biomaterial, which has been fabricated via the freeze-casting method, consisted of two layers of sponge-like chitosan and a layer of dried dBAM. The porous chitosan scaffold meliorated blood coagulation and swelling properties, while $\mathrm{dBAM}$ provided the essential growth factors and collagen content for wound healing. To retain the biomedical and architectural properties of dBAM, poly(ethylene glycol) diglycidyl ether (PEGDGE) was applied as a cross-linking agent. According to their data, this wound dressing had better biocompatibility, air permeability, improved swelling ability, and mechanical properties in comparison with each material alone. Additionally, this membrane promoted diabetic wound healing ratio $(87.67 \%$ at day 8 on average) to the stage that even sebaceous gland, hair follicles, and collagen fibers with parallel organizations were observed (at day 14).

In addition to this, following their previous study, Adamowicz et al. (2020) introduced a new composite biomaterial based on AM and graphene to create an interface between cells and external stimuli to replace neural network for urinarybladder TE. To evaluate the properties of this structure, they seeded it with SMCs and urothelial cells. According to their published results, the growth of SMCs increased due 
to the electrical stimulation applied through the biocomposite structure. Moreover, they observed in vitro contractile response of SMCs, which indicates the effectiveness of this structure in transferring electrical stimulation.

\section{Amniotic Membrane as a Coating}

In some cases, $A M$ is used as a coating to improve the biocompatibility of other materials. Currently, the conventional method for hernias treatment is the use of polypropylene (PP) mesh, which causes some complications such as tissue adhesion (Najibpour et al., 2016). In several in vivo models (rat and rabbit), the AM has been used as a coating on PP mesh without any suture or addition of adhesive material. The effectiveness of AM-coated PP mesh in comparison with single PP mesh on the prevention of abdominal adhesions was assessed. Findings show less adhesion and inflammation, higher epithelialization, and wound healing improvement when the AM was applied (Najibpour et al., 2016; Soylu et al., 2018). Rashid et al. conducted a similar study in the rat model. They used BAM with a coating of PEG on the abdominal side of the PP mesh. The lowest adhesion percentage was observed in the experimental group in which PP mesh was covered with BAM and 5\% PEG. However, this study shows that BAM alone was not as efficient (Rashid et al., 2018).

In another study, Jiang et al. (2007) fabricate AM-covered stainless steel (SS). In this study, Jiang et al. compared AM to porcine small intestinal submucosa (PSIS), which had previously been utilized as a stent coverage (Toyota et al., 2002). Although stretch stress tests showed that cryopreserved AM is not as extensible as PSIS (AM in comparison with PSIS: tearing length of 9.39 and $12.95 \mathrm{~mm}$; maximum stress of 3.99 and $12.94 \mathrm{MPa}$; maximum strain of 0.47 and $0.65 \mathrm{~mm} / \mathrm{mm}$ ), stress-strain curves indicated that AM is more consistent than PSIS and is an excellent elastic membrane as a cover for stent as it also is blood compatible and has minimum immune response. According to their results, internally AM-covered stent kept the arterial lumen smooth while it had a better chance of AM detachment. On the other hand, externally AM-covered stent connected the stent firmly to the vessel with minor vessel injury but it did not have any effect on enhancing arterial lumen smoothness.

In another study, AM has been utilized in a composition with polyvinyl alcohol (PVA) hydrogel to improve PVA's biological properties. PVA is one of the well-suited candidates for corneal transplantation, but its limited biocompatibility has made some challenges for its in vivo application. To address this problem, Uchino et al. (2007) designed a hybrid polymer based on PVA hydrogel and dAM. In order to do this, collagen immobilizedPVA hydrogel was fabricated and coated with AM using a tissue adhesive component consisting of collagen and citric acid as a cross-linker. This structure improved corneal epithelialization after 2 weeks in comparison with PVA-collagen hybrid, which resulted in epithelium loss in the same period (Figure 3F).

The most recent study on AM as a coating was conducted by Akyürek et al. (2020) who evaluated the efficiency of AMcoated silicon breast implant on capsule formation in vivo. Based on Akyürek et al. hypothesis, the anti-inflammatory and antifibrinolytic effect of AM can be useful in the prevention of the most severe complication in silicone breast implants, which is capsule contraction. According to their results, AM retained its integrity after 3 weeks in $80 \%$ of rats, but it was not detected after 12 weeks. However, their results show that composite implants which remained for 12 and 24 weeks significantly reduced capsule thickness in comparison with bare silicon (p:0.015, p:0.012) while the difference between capsule thickness after 3 weeks was not statistically significant between two groups (p:0.674).

\section{Composites Based on Particulated Amniotic Membrane}

Another approach that has been developed by some studies is to enhance the biological properties of other materials by the addition of particulated AM (pAM) before the final fabrication process. Different tools have been utilized for AM pulverization, which is all accessible and straightforward, such as mortar and pestle (Dewey et al., 2020), and tissue grinder (Zhang et al., 2019). One example of these constructs has been developed for the treatment of oral mucosal defects, which has always been challenging for AM. Zhang et al. (2019) have introduced an alternative approach for treating these defects using dAM in combination with methacrylated gelatin (GelMA). This composite substitute was prepared with the addition of decellularized amniotic particles (dAP) to GelMA solution following with a curing process initiated by photosensitive acylphosphinate. Their proposed structure has the mechanical strength (maximum load value of $1.04 \pm 0.03 \mathrm{MPa}$ ) and adhesion of GelMA blended with biological cues of dAM. Their results show that this scaffold significantly increased the number of neovascularization in a chick chorioallantoic membrane (CAM) assay (more than $10 \mathrm{~mm}^{2}$ compared to GelMA). Additionally, while it did not cause any postoperative infection or allergy reaction in rabbit models, this 3D porous scaffold improved angiogenesis and was suitable for the treatment of oral mucosal defects.

Hortensius et al. have developed another composite structure based on pAM for tendon regeneration. In two studies, they combined collagen-glycosaminoglycan (CG) scaffolds with dAM to promote tendon repair. In the first study, they hypothesized that the addition of the ECM found in low inflammatory environments to the scaffold would modify the host immune responses (Hortensius et al., 2016). To examine this, they incorporated chondroitin sulfate (CS), hyaluronic acid (HA), and particulate dAM into collagen suspensions with different ratios and fabricated the final scaffolds with freeze-drying. According to their results, scaffolds containing HA or dAM increased the metabolic activity of tenocytes in comparison with other scaffolds, especially in high inflammatory media after 7 days. Besides, their findings show that scaffolds based on $\mathrm{dAM}$ and HA maintain their anti-inflammatory features within a collagen-based scaffold and alter the pro-inflammatory response associated with scar formation during tendon healing. However, these scaffolds did not have the required mechanical strength to be utilized for direct tendon regeneration (elastic modulus of $1.065 \pm 0.083 \mathrm{KPa}$ ). In the next study, they explored two different methods for the fabrication of these scaffolds (Hortensius et al., 2018). The first one was the same as the 
fabrication method used in the first study, and the other method was based on the traditional collagen-chondroitin sulfate (C/CS) scaffold with a layer of dAM wrapped around it. According to their results, these scaffolds affected the response of MSCs to inflammatory challenges in the early stages, and it may be a potential biomaterial for enhancement of tendon regeneration.

Another composite structure based on pAM and mineralized collagen scaffold has been developed recently by Dewey et al. for bone repair. The fabrication method of this scaffold was similar to the one described by Hortensius et al. in terms of dAM pulverization before adding it to collagen suspension; however, in this study, the composition of the collagen scaffold was slightly different from those reported by Hortensius et al. (Dewey et al., 2020). Based on the results reported by this group, the addition of dAM to collagen scaffold resulted in smaller pore size (approximately $60 \mu \mathrm{m}$ ) and higher Young's modulus, collapse stress, and collapse strain. Additionally, while the collagen scaffold without any dAM supported cell viability and osteogenic differentiation more, the final mineral formation and osteogenesis in response to the inflammatory challenge was enhanced in mineralized collagen-AM scaffold after 28 days.

\section{AMNIOTIC MEMBRANE EXTRACT}

Despite beneficial chemical and physical characteristics of AM, a significant problem associated with its utilization is the difficulty in providing fresh AM (Kang et al., 2013). Different approaches have been developed to increase AM shelf life, such as freezedrying or cryopreserving the AM. An alternative approach is to use amniotic membrane extract (AME). AME contains almost all of the therapeutic components of the cryopreserved AM (Dudok et al., 2015); it is rich in growth factors such as EGF, HGF, bFGF, protease inhibitors, and HC-HAPTX3, which is a matrix component with ant-inflammatory, anti-angiogenesis, and antiscarring effects (Mahbod et al., 2014; Mamede and Botelho, 2015; Stachon et al., 2015). Furthermore, AME can be easily preserved and be sterilized through filtration.

Additionally, as a result of a study conducted on the antibacterial effect of AME/CME (chorionic membrane extract) against $S$. pneumoniae, it has been proven that as well as AM/CM, AME/CME has several antimicrobial peptides and proteins that inhibit bacterial cell growth and biofilm formation (Yadav et al., 2017). These extracts, in combination with P-S antibiotic solution, inhibit in vitro biofilm growth and eradicate preestablished biofilms. This effect has been further investigated by Park et al. (2020) in a recent study. They aimed to assess the AME effect on the growth of the middle ear (ME) mucosa in response to otitis media (OM) induced by non-typeable Haemophilus influenzae (NTHi). According to their results, AME influenced mucosal proliferative response in a dose-dependent manner. However, due to the limitations of this study, it is hard to interpret their results.

The anti-inflammatory effect of AM is preserved in its extract form by the same pathway, which is the induction of macrophage apoptosis (Li et al., 2006). He et al. (2008) proved this activity by studying RAW264.7 morphological alternation, cell growth, and apoptosis in resting and activated macrophages in a medium containing AME. Their results indicate a reduction in cell spreading mediated by a reduction in actin filament intensity in AME-treated cells, suppression of cell growth, and cell apoptosis induction. According to He et al. (2009) and Shay et al. (2011), the main component which is partially associated with the antiinflammatory and anti-scarring effect of AME is HC-HA complex (hyaluronan and heavy chains of inter- $\alpha$-inhibitor). In another study, Laranjeira et al. evaluated the anti-inflammatory effect of AME on T cells and antigen-presenting cells. According to their results, AME inhibits the inflammatory response of $\mathrm{T}$ cells and reduces the proportion of $\mathrm{T}$ cells that produce cytokines (Laranjeira et al., 2018). However, this effect is not comprehensible for APCs. Overall, they showed that the antiinflammatory effect of AME is mostly due to its direct effect on the proliferation capacity of $\mathrm{T}$ cells in response to mitogen activation. Additionally, it inhibits the expression of proteins that have a cytotoxic function.

\section{Preparation of Amniotic Membrane Extract}

Different approaches have been developed for the preparation of AME without consistent standardization. The most convenient method consists of washing previously isolated and screened AM with a sterile saline solution containing $1 \%$ antibiotic cocktail (penicillin, streptomycin, and neomycin), submerging $\mathrm{AM}$ in the liquid nitrogen, slicing the frozen AM into small pieces, and manually morselizing it to a fine powder and homogenizing it with normal saline or PBS. Following that, the mixture is centrifuged. The supernatant is collected and centrifuged again (Figure 4A) and finally sterilized by passage through a filter. In other methods, cryopreserved or dehydrated AM is micronized or pulverized (Murri et al., 2018). In some cases, AME was obtained from a decellularized AM (Shakouri-Motlagh et al., 2019).

Mahbod et al. compared the effect of different preparation methods on the total amount of protein and HGF to introduce the best method for AME preparation. Also, they studied the effect of storage conditions on AME by testing the stability of the HGF under different periods and temperatures (Mahbod et al., 2014). In this study, they first dried some AMs partially (PDAM) and others wholly (CDAM) and then homogenized some of CDAM and pulverized the remaining CDAM in addition to PDAM. According to their results, pulverization of the AM to prepare AME results in 20\% more extractable factors in comparison with homogenization as the cellular damage caused by liquid nitrogen results in more protein and HGF emerge. In addition, pulverization is a much easier method, and repeating it up to three times will result in more extractable HGF (almost double). Furthermore, a comparison of different storage conditions revealed that HGF is resistant to repeated freeze-thawing. Additionally, they concluded that while storage temperature does not have any significant effect on $\mathrm{HGF}$ level, keeping $\mathrm{AME}$ at $-170^{\circ} \mathrm{C}$ results in the least drop in HGF after 6 days. However, this factor is unstable over long-term storage at $-170^{\circ} \mathrm{C}$. Finally, they showed that 


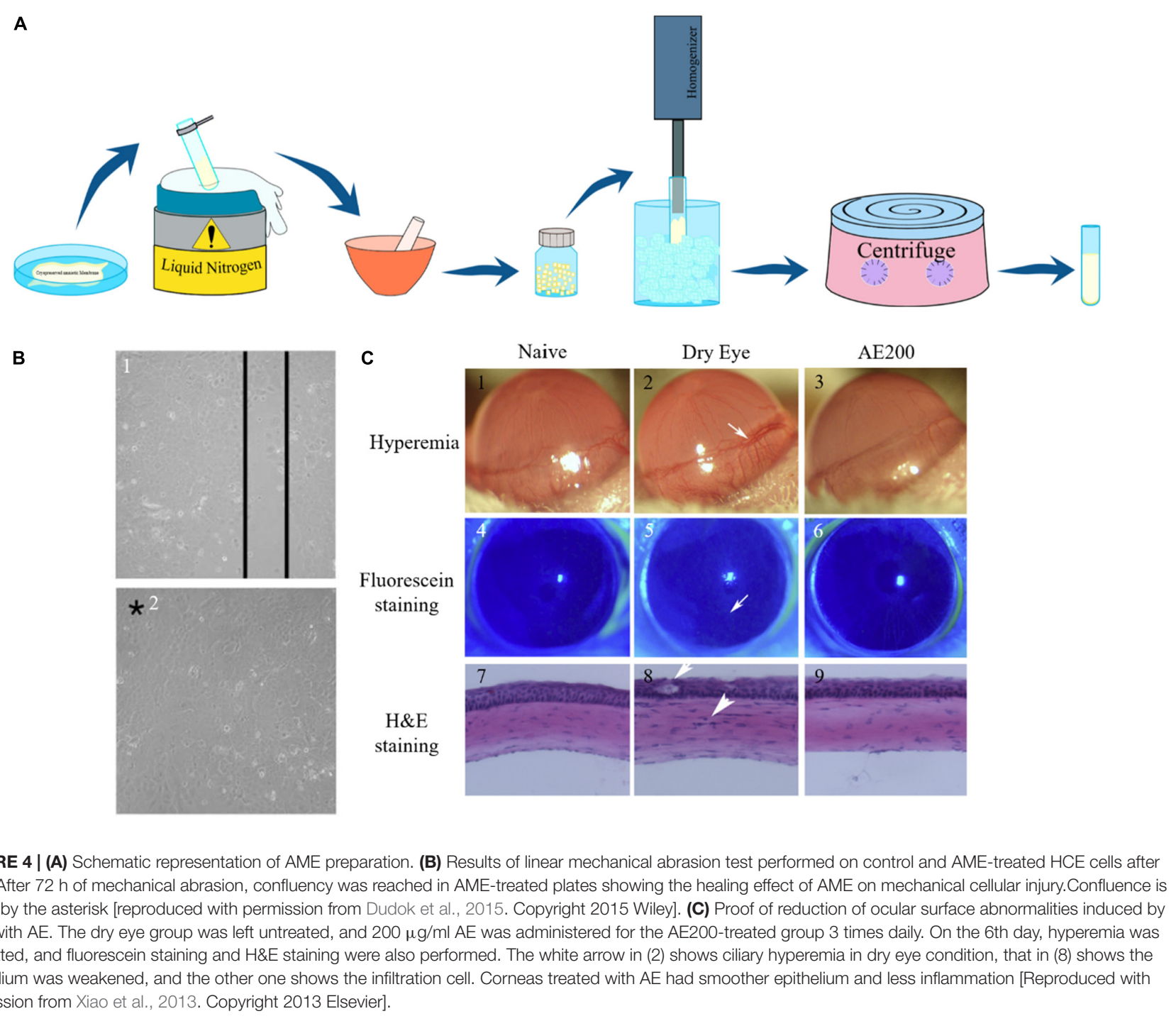

the utilization of a $0.2-\mu \mathrm{m}$ filter for sterilization of the AME has no significant effect on HGF and protein levels. This result indicates that it is possible to prepare AME under unsterile conditions.

\section{Amniotic Membrane Extract Applications}

Here we have reviewed the most significant results of the studies conducted on the therapeutic effect of AME in different fields such as ocular surgery, wound healing, and stem cell expansion. A summary of this information is reported in Table 3.

\section{Ophthalmology}

Amniotic membrane is rich in growth factors and structural proteins that influence the corneal healing process from different aspects such as the promotion of re-epithelialization, LSC migration, inhibition of cell apoptosis, and maintenance of epithelial progenitor cells within the LSC niche (Rauz and Saw, 2010; Malhotra and Jain, 2014). Like AM, AME has beneficial bioactive factors efficient in the treatment of ocular surface disorders. As these factors suppress inflammation and neovascularization and promote epithelialization, some studies have shown that AME is a useful substrate for ocular chemical burn treatment (Kim and Tseng, 1995; Choi et al., 2011; Westekemper et al., 2017). According to these studies, AME has a direct influence on decreasing ocular surface inflammation and symptomatic relief. Moreover, its re-epithelialization effect induces proliferation and differentiation in corneal epithelial cells, and it can suppress neovascularization in the cornea after mild to moderate chemical burns (Jiang et al., 2006; Choi et al., 2009; Liang et al., 2009; Dudok et al., 2015). Additionally, it has been observed that AME has protective effects against dry eye disease (Liu et al., 2020).

Although AM transplantation (AMT) is one of the methods for ocular surface treatment in the case of an ocular chemical burn, it may also cause surgical trauma. Besides, the topical use of AME is a much simpler approach as it does not require surgical intervention and has lower morbidity (Mahbod et al., 2014). On 
TABLE 3 | Summary of studies based on AME.

\begin{tabular}{|c|c|c|c|c|c|}
\hline Author, year & Therapeutic goal & $\begin{array}{l}\text { Experimental } \\
\text { settings }\end{array}$ & $\begin{array}{l}\text { Target } \\
\text { tissue/cells }\end{array}$ & Conclusion & References \\
\hline Chang, 2002 & $\begin{array}{l}\text { Inflammatory skin } \\
\text { diseases }\end{array}$ & In vitro & HaCaT cells & $\begin{array}{l}\text { AME can be utilized to treat inflammatory skin diseases } \\
\text { such as UV-induced skin diseases as it decreases the } \\
\text { induction of iNOS mRNA and generation of NO in HaCaT } \\
\text { cell by UVB radiation and can protect cells from death or } \\
\text { morphological alteration }\end{array}$ & $\begin{array}{l}\text { Chang et al., } \\
2002\end{array}$ \\
\hline Li, 2008 & $\begin{array}{l}\text { Stem cell preservation } \\
\text { and expansion }\end{array}$ & In vitro & AMSCs & $\begin{array}{l}\text { AME like AM has the potential to help AMSCs maintain their } \\
\text { progenitor status and can reverse differentiated } \\
\text { myofibroblasts to a fibroblast phenotype }\end{array}$ & Li et al., 2008 \\
\hline He, 2008 & Anti-inflammatory agent & In vitro & RAW 264.7 cells & $\begin{array}{l}\text { AME retains anti-inflammatory activities and does so by } \\
\text { downregulating activation and inducing apoptosis in } \\
\text { macrophages }\end{array}$ & He et al., 2008 \\
\hline He, 2009 & $\begin{array}{l}\text { Ocular surface } \\
\text { reconstruction }\end{array}$ & In vitro & $\begin{array}{l}\text { Human corneal } \\
\text { fibroblasts, RAW } \\
264.7 \text { cells }\end{array}$ & $\begin{array}{l}\text { The HC-HA complex is an active component in AM } \\
\text { responsible for the suppression of TGF- } \beta 1 \text { promoter activity, } \\
\text { linkable to its anti-scarring and anti-inflammatory effect }\end{array}$ & He et al., 2009 \\
\hline Choi, 2013 & Wound healing & In vivo & $\begin{array}{l}\text { Sprague Dawley } \\
\text { rats }\end{array}$ & $\begin{array}{l}\text { In comparison with the commercial product, the } \\
\text { double-layered AME-loaded wound dressing enhanced } \\
\text { wound healing }\end{array}$ & $\begin{array}{l}\text { Choi et al., } \\
2014\end{array}$ \\
\hline Xiao, 2013 & Dry eye & In vivo & BALB/c mouse & $\begin{array}{l}\text { Topical application of AME on BAC-induced dry eye } \\
\text { resulted in improved clinical symptoms of dry eye, reduced } \\
\text { corneal inflammation, decreased squamous metaplasia, } \\
\text { protected corneal epithelial cells and increased their } \\
\text { proliferation, and increased the density of goblet cells }\end{array}$ & $\begin{array}{l}\text { Xiao et al., } \\
2013\end{array}$ \\
\hline Kang, 2013 & Wound healing & In vitro and in vivo & $\begin{array}{l}\text { Primary human } \\
\text { foreskin fibroblasts } \\
\text { New Zealand white } \\
\text { rabbit }\end{array}$ & $\begin{array}{l}\text { Intradermal injections of AME fluid on wound sites resulted } \\
\text { in increased wound closure rate and promoted epidermal } \\
\text { and dermal regeneration without causing undesirable } \\
\text { hyperproliferation of damaged tissue }\end{array}$ & $\begin{array}{l}\text { Kang et al., } \\
2013\end{array}$ \\
\hline Lee, 2016 & $\begin{array}{l}\text { Ocular surface } \\
\text { disorders }\end{array}$ & In vitro & $\begin{array}{l}\text { Human corneal } \\
\text { epithelial cells }\end{array}$ & $\begin{array}{l}\text { Homogenized AME of less than } 3 \mathrm{kDa} \text { had a higher } \\
\text { capacity in the reduction of inflammation }\end{array}$ & Lee et al., 2016 \\
\hline Vojdani, 2016 & Stem cell therapy & In vitro & HUCBMSC & $\begin{array}{l}\text { AME has the potential to enhance the proliferation capacity } \\
\text { of HUCBMSCs without influencing their morphology and } \\
\text { differentiation capacity }\end{array}$ & $\begin{array}{l}\text { Vojdani et al., } \\
2016\end{array}$ \\
\hline Go, 2016 & osteogenic effects & In vitro & MG-63 & $\begin{array}{l}\text { Unlike CME, the EGF content of AME negatively regulated } \\
\text { the osteogenic differentiation of MG- } 63 \text { cells. However, it } \\
\text { can be modified with EGFR inhibitors to modulate the bone } \\
\text { density or calcification during bone regeneration }\end{array}$ & Go et al., 2016 \\
\hline Yadav, 2017 & $\begin{array}{l}\text { The antibacterial effect } \\
\text { of AME against S. } \\
\text { pneumonia }\end{array}$ & In vitro and in vivo & $\begin{array}{l}\text { Microtiter plate } \\
\text { assay and OM rat } \\
\text { model }\end{array}$ & $\begin{array}{l}\text { AME/CME contains essential antimicrobial proteins and } \\
\text { peptides to inhibit S. pneumoniae growth in both planktonic } \\
\text { and biofilm states }\end{array}$ & $\begin{array}{l}\text { Yadav et al., } \\
2017\end{array}$ \\
\hline Litwiniuk, 2017 & Cell growth & In vitro & $\begin{array}{l}\text { HaCaT, Wi-38, } \\
\text { HECa-10 }\end{array}$ & $\begin{array}{l}\text { The placental portion of AM stimulates both fibroblasts and } \\
\text { keratinocytes and is best suited for applications related to } \\
\text { wound healing. On the other hand, the cervical portion of } \\
\text { AM provide from C-section is a better option for the } \\
\text { treatment of ocular diseases as it stimulates epithelialization }\end{array}$ & $\begin{array}{l}\text { Brown et al., } \\
1989\end{array}$ \\
\hline $\begin{array}{l}\text { Baradaran-rafii, } \\
2017\end{array}$ & LSC transplantation & In vivo & Human eyes & $\begin{array}{l}\text { Application of AM as a supporter (niche/scaffold) and } \\
\text { AMEED as the promoter of limbal/epithelial cell growth may } \\
\text { be a promising surgical procedure for LSC cultivation }\end{array}$ & $\begin{array}{l}\text { Baradaran-Rafii } \\
\text { et al., } 2018\end{array}$ \\
\hline $\begin{array}{l}\text { Laranjeira, } \\
2018\end{array}$ & Allergic disorders & In vitro & Human PBMCs & AME induces anti-inflammatory effect on T cells & $\begin{array}{l}\text { Laranjeira et al., } \\
2018\end{array}$ \\
\hline
\end{tabular}


TABLE 3 | Continued

\begin{tabular}{|c|c|c|c|c|c|}
\hline Author, year & Therapeutic goal & $\begin{array}{l}\text { Experimental } \\
\text { settings }\end{array}$ & $\begin{array}{l}\text { Target } \\
\text { tissue/cells }\end{array}$ & Conclusion & References \\
\hline Motlagh, 2018 & Stem cell therapy & In vitro & Decidual MSCs & $\begin{array}{l}\text { Coatings based on AME maintain or reduce the size of } \\
\text { DMSCs and promote their proliferation, osteogenic, and } \\
\text { adipogenic differentiation }\end{array}$ & $\begin{array}{l}\text { Shakouri- } \\
\text { Motlagh et al., } \\
2019\end{array}$ \\
\hline $\begin{array}{l}\text { Faridvand, } \\
2018\end{array}$ & $\begin{array}{l}\text { Myocardial hypoxia } \\
\text { injury }\end{array}$ & In vitro & $\begin{array}{l}\text { H9c2 } \\
\text { cardiomyocytes }\end{array}$ & $\begin{array}{l}\text { Proteins present in AME have cardioprotective effects in } \\
\text { hypoxic conditions by reducing oxidative stress and } \\
\text { inflammatory response and modulating apoptosis }\end{array}$ & $\begin{array}{l}\text { Faridvand et al., } \\
2018\end{array}$ \\
\hline Farzan, 2018 & Wound healing & In vivo & Rat skin & $\begin{array}{l}\text { AME as well as deferoxamine has the potential to induce } \\
\text { angiogenesis during wound healing }\end{array}$ & $\begin{array}{l}\text { Farzan et al., } \\
2018\end{array}$ \\
\hline Asl, 2019 & $\begin{array}{l}\text { Corneal surgery and } \\
\text { cell therapy }\end{array}$ & Ex vivo and in vivo & LSCs and rabbit & $\begin{array}{l}\text { AMEED enhances LSC proliferation and decreases } \\
\text { epithelium healing duration by } 1 \text { day in comparison to the } \\
\text { control group }\end{array}$ & Asl et al., 2019 \\
\hline $\begin{array}{l}\text { Fardivand, } \\
2019\end{array}$ & $\begin{array}{l}\text { Myocardial hypoxia } \\
\text { injury }\end{array}$ & In vitro & $\mathrm{H} 9 \mathrm{c} 2$ & $\begin{array}{l}\text { AME proteins protect cardiomyocytes in hypoxic conditions } \\
\text { through the regulation of } \mathrm{HO}-1 \text { by } \mathrm{Nrf} 2 \text { activation }\end{array}$ & $\begin{array}{l}\text { Faridvand et al., } \\
2019\end{array}$ \\
\hline $\begin{array}{l}\text { Fardivand, } \\
2020\end{array}$ & Cardiotoxicity & In vitro & $\mathrm{H} 9 \mathrm{c} 2$ & $\begin{array}{l}\text { AME has the potential to suppress the cardiotoxicity } \\
\text { induced by DOX through inhibition of apoptosis and } \\
\text { oxidative stress }\end{array}$ & $\begin{array}{l}\text { Faridvand et al., } \\
2020\end{array}$ \\
\hline Liu, 2020 & Dry eye disease & In vitro & $\begin{array}{l}\text { Human corneal } \\
\text { epithelial cells }\end{array}$ & $\begin{array}{l}\text { Through the upregulation of MMP- } 8 \text { and downregulation of } \\
\text { IL-1 } \beta \text { and TNF- } \alpha, \text { AME protects corneal epithelial cells } \\
\text { against benzalkonium chloride }\end{array}$ & Liu et al., 2020 \\
\hline Park, 2020 & $\mathrm{OM}$ & In vitro & ME mucosa of rats & $\begin{array}{l}\text { Possibly AME exerts anti-proliferative and anti-inflammatory } \\
\text { effects on infected ME mucosa }\end{array}$ & $\begin{array}{l}\text { Park et al., } \\
2020\end{array}$ \\
\hline Shabani, 2020 & Ocular surface disease & In vitro & HUVECs & $\begin{array}{l}\text { AME loaded chitosan-dextran sulfate nanoparticles } \\
\text { decreased the proliferation of endothelial cells }\end{array}$ & $\begin{array}{l}\text { Shabani et al., } \\
2020\end{array}$ \\
\hline
\end{tabular}

the other hand, in comparison with AMT, AME has a comparable effect on epithelialization, suppression of inflammation, and corneal neovascularization (Jiang et al., 2006; Shahriari et al., 2008). AME has also been applied in the form of AME eye drop (AMEED) to treat ocular disorders. Unlike AMT, AMEED makes it possible to deliver therapeutic substances for a more extended period without any surgical intervention (Kordić et al., 2013; Xiao et al., 2013; Dudok et al., 2015). However, AMEED lacks the physical and structural properties of AM (Baradaran-Rafii et al., 2018).

To evaluate AME efficiency in the treatment of acute ocular chemical burn, Sheha et al. (2010) conducted a study. In this study, they added AME to the conventional treatment of acute ocular chemical burn after 2 days of injury and reported that not only did it reduce the pain, but also a reduction in the inflammation was observed in all of the cases. In addition to this, they reported rapid healing of the epithelial in the defect site (within 11 days on average), and no neovascularization in the follow-up period was observed.

Additionally, AME has been applied in some studies with a focus on cornea injury. For instance, it has been noted that AMEED improves the healing of the corneal persistent epithelial defects (Kordić et al., 2013). Dudok et al. (2015) conducted a study to evaluate primary human corneal epithelial (HCE) cell's response to AME in case of ocular surface injuries and to provide evidence of the safety and cellular benefits of AME on HCE cells. They proved that $0.1 \%$ AME solution has a significant influence on mechanical cellular injury due to its effect on epithelialization (Figure 4B). Based on their results, pretreatment of HCE and limbal cell cultures with $0.1 \%$ AME prior to tertiary butyl hydroperoxide $(\mathrm{t}-\mathrm{BOOH})$ treatment enhances cellular metabolic activity in comparison with cells treated with $\mathrm{t}-\mathrm{BOOH}$ alone (respectively $73.3 \%$ vs. $66.0 \%$ and $91.0 \%$ vs. $82.0 \%$ ). In a recent study, Shabani et al. (2020) utilized nanoparticles to release AME in a more controlled manner for the treatment of cornea surface injuries. According to their results, chitosan-dextran nanoparticles containing AME were more effective than AME alone in the inhabitation of corneal neovascularization.

Moreover, due to its anti-inflammatory effect, AME may be a suitable therapeutic option for the treatment of dry eye as inflammation is the primary cause of this disease. This inflammation may be induced by squamous metaplasia, epithelial apoptosis, or goblet cell loss (Kunert et al., 2002; Pflugfelder et al., 2008; Xiao et al., 2013). Although AMT has been applied for the treatment of dry eye, AME may be a better option as it does not have transplantation complications such as suture-related scars and hospitalization. Xiao et al. (2013) evaluated the therapeutic effect of AME on dry eye induced by benzalkonium chloride (BAC). According to their study, AME is capable of reversing the pathological changes associated with dry eye by suppressing the infiltration of inflammatory cells, decreasing global cell apoptosis, alleviating squamous metaplasia, and promoting epithelial cell proliferation. Overall, they concluded that 1.5 and $3 \mathrm{mg}$ AME per day stabilizes tear film, maintains the integrity of epithelium, and alleviates ocular surface inflammation, which all lead to improvement of the clinical manifestation of BAC-induced dry eye in the mouse model (Figure 4C).

Lee et al. (2016) conducted a study to prove the antiinflammatory effect of AME on human corneal epithelial cells (hCECs) and showed that it was a more efficient antiinflammatory agent than negative control without inducing 
apoptosis. Besides, they attempted to identify which part of AME is responsible for this effect. According to their data, the fraction of AME smaller than $3 \mathrm{kDa}$, which included diverse molecules such as peptides, amino acids, and nucleotides, had more therapeutic, especially anti-inflammatory effect in comparison with larger molecules. Altogether, they proved that AME is a suitable therapeutic approach for mild ocular surface disorders, which are combined with inflammation, such as dry eye syndrome.

Amniotic membrane has been known as a substrate that can support LSC expansion (Plummer, 2009). Although the routine method for LSC expansion involves FBS usage (De Luca et al., 2006; Baylis et al., 2011), it accompanies some challenges such as possible disease transmission and accumulation of bovine antigens, which can lead to activation of the immune response, resulting in transplantation failure (Gregory et al., 2006; Sundin et al., 2007). Thus, a suitable replacement for FBS could be AM or AME, which not only are free from animal antigens but also promote ocular surface reconstruction (Paolin et al., 2016). Additionally, researches indicate that AME reduces inflammation, induces re-epithelialization, and improves patients' symptoms within 15-20 days after treatment (Liang et al., 2009; Kordić et al., 2013; Xiao et al., 2013). The molecular mechanism of this therapeutic effect of AME has been reviewed by Tseng (Mamede and Botelho, 2015). Asl et al. (2019) evaluated the effect of AMEED on ex vivo LSC expansion. According to their results, the optimum dose of AMEED for LSC culture was $0.1 \mathrm{mg} / \mathrm{ml}$, while in an in vivo model of rabbit, this dose increased to $1 \mathrm{mg} / \mathrm{ml}$. Additionally, they proved that AMEED limits LSC differentiation, and as AMEED growth factors have a dosedependent effect, their accumulation should be avoided. Another exciting outcome of their study was that AMEED growth factors are stable for at least 10 months at $-70^{\circ} \mathrm{C}, 7$ days at $2-8^{\circ} \mathrm{C}$, and 2 days at room temperature. Overall, AMEED which increases LSC proliferation in vitro and accelerates re-epithelialization in vivo is a much more straightforward, more convenient, and less complicated approach in comparison with AMT for corneal defects as it is not associated with progression of corneal surface disorders, corneal thinning or perforation, calcification, and inflammation (Sangwan et al., 2007; Kaup et al., 2008; Asl et al., 2019). In addition, due to AMT lyse after 1-2 weeks, it requires repeated transplantation while AMEED does not have such an issue.

Baradaran-Rafii et al. (2018) hypothesized that utilization of AM in combination with its extract would influence LSC cultivation in a more sensible and inexpensive way. Conventionally, LSCs are expanded ex vivo and transplanted with the lowest differentiation to corneal cells. However, it is an expensive and time-consuming procedure that requires special laboratory devices and is not accessible to all patients (Ramaesh and Dhillon, 2003). To overcome these challenges, BarardaranRafii et al. developed an alternative single-step procedure that is accessible for all patients without any expensive laboratory facilities. In their proposed surgery, like the conventional method, a small limbal biopsy, which has been harvested from the healthy eye, is transferred to the damaged eye, which is previously covered with a cryopreserved AM. Unlike the conventional method, they added supplemental AMEED postsurgery to promote corneal epithelial healing. According to their results, in those cases where AMEED was not administrated, a persistent epithelial defect was observed. They concluded that autologous limbal tissue in combination with $\mathrm{AM}$ as a niche and AME as a supporter could be helpful for less expensive, more rapid, and more straightforward in vivo cultivation of LSCs.

\section{Wound Healing}

AM extract has also been investigated for wound healing applications by some groups. It has been applied as a drug in a double-layered wound dressing containing a layer of PVA (6.7\%) and an AME-loaded layer of sodium alginate (0.5\%) to improve wound healing characters and gel properties (Choi et al., 2014). It was also utilized solely in other studies. Among them is the research conducted by Kang et al. (2013), evaluating the feasibility of freeze-dried AME as a wound healing substrate. According to their results, AME injection promotes epidermal and dermal regeneration while suppresses their overproliferation and improves the orientation of dermal collagen bundles in a dose-dependent manner.

Additionally, AME is a valuable source for inflammatory skin diseases such as ultraviolet-induced skin diseases (Chang et al., 2002). Chang et al. (2002) have evaluated the effect of AME on the expression of nitric oxide synthase (NOS) mRNA in $\mathrm{HaCaT}$ cells, which is expressed during many inflammatory diseases and is triggered by UV radiation. According to their data, AME, at a specific dose, downregulates the induction of this mRNA upon UV irradiation and protects cells from death or morphological changes.

Angiogenesis, which is one of the most crucial parts of wound healing, is particularly challenging in chronic wounds such as diabetic and venous leg ulcers. Various substrates with angiogenic effects have been studied to accelerate the wound healing rate. Among these substrates are AME and deferoxamine. Farzan et al. (2018) compared the angiogenic effect of these agents separately and in combination with each other. According to their results, AME increases angiogenesis by promoting angiogenic indicators. Recent studies have shown that the angiogenic effect of AME is partially attributed to its chemokine contents and growth factors, which induce endothelialization. In comparison with deferoxamine, which has an excellent capacity for revascularization, there is no significant difference between the number of angiogenic markers of AME and deferoxamine, although their mechanism of action is different. It is noteworthy that the combination of these agents did not surpass the single groups in this study.

\section{Heart}

It has been previously shown that AME has beneficial effects on mechanical cell injuries and suppression of oxidative stress (Dudok et al., 2015). Fardivand et al. conducted a study to evaluate the molecular effect of AME proteins on suppressing H9c2 cells under hypoxic conditions (Faridvand et al., 2018). They showed that while hypoxia alters cardiomyocytes' viability, apoptosis, oxidative stress, and inflammation, proteins present in the AME can support cells in hypoxic conditions and 
decrease their apoptosis. Additionally, AME suppressed hypoxiainduced ROS generation. Overall, the cardioprotective effect of $\mathrm{AM}$ is associated with its protein content, which is present in AME and can regulate cell apoptosis and inflammatory responses under ischemic conditions. In another study, they examined the mechanism underlying this protective effect of AME proteins on the same cell line (H9c2 cells) under hypoxic conditions (Faridvand et al., 2019). According to their results, the upregulation of HO-1 and Nrf2 genes in AME treatment results in increased cell survival. In a more recent study, Fardivand et al. evaluated the cardioprotective effect of AME against cardiotoxicity induced by doxorubicin (DOX) (Faridvand et al., 2020). According to this study, the protein content of AME, which has the potential to modulate apoptosis, Ca2+ homeostasis, and inflammation, protects $\mathrm{H} 9 \mathrm{c} 2$ cardiomyocytes against the cytotoxicity induced by DOX.

\section{Leg Ulcers}

Amniotic membrane has been clinically utilized for the treatment of chronic leg ulcers because of the influence it has on epithelialization (Mermet et al., 2007). Tauzin et al. (2014) conducted a preliminary study to evaluate the effect of AME on ulcer fibroblast (UF) in comparison with normal fibroblast (NF). Although their study was limited to the use of singlepatient cells, their results show that UF was barely stimulated by AME while NF shows some responses. They developed different hypotheses for this phenomenon, such as the absence of appropriate receptors on UF and impaired signal transduction. They concluded that the beneficial therapeutic effect of AM on leg ulcer may be related to the effect of this substrate on keratinocytes and/or the regulation of inflammation. In a recent study, Alamouti et al. (2019) clinically evaluated the efficiency and safety of AME on diabetic ulcers. According to their results, both small $\left(\leq 500 \mathrm{~mm}^{2}\right)$ and big $\left(\geq 500 \mathrm{~mm}^{2}\right)$ wounds significantly healed after 4 weeks of treatment with AME and their treatments were completed after 6 weeks. Although they concluded that AME has a better effect on smaller wounds and attribute to their wound healing by stimulating keratinocyte migration.

\section{Mesenchymal Stromal Cells}

Stem cell preservation and expansion have always been a challenge in clinical cell therapy approaches. Different approaches have been developed to increase the proliferation capacity of stem cells and preserve their stemness, such as adding growth factors. For instance, bFGF is an additional factor to increase MSC proliferation capacity; however, it also affects their differentiation potential, which is not favorable in many studies (Sotiropoulou et al., 2006; Nguyen et al., 2015). As a substitute, Vojdani et al. (2016) investigated the effect of AME on the proliferation capacity of human umbilical cord MSCs (HUCBMSCs). According to their results, AME has the potential to enhance the proliferation rate of HUCBMSCs without altering their morphology and differentiation potential.

Moreover, the anti-fibrotic effect of AM has partially arisen from its regulatory effect on growth factors that trigger myofibroblast differentiation (Espana et al., 2004). Li et al. proved that the soluble fraction of AME also possesses this potential.
They also demonstrated that as myofibroblasts differentiated from AM stromal cells (AMSCs) cultured in a medium which contains AME, they can revert to a fibroblast phenotype (Li et al., 2008). From this data, they have concluded that AM has soluble factors that can control the differentiation of MSC. This action is accomplished by downregulation of TGF- $\beta$, which, together with mechanical stress, has an essential effect on myofibroblast differentiation. These findings may lead to the extraction of specific components from AME or AM stromal extract (ASE) to be used in anti-scaring therapies as well as stem cell preservation and expansion.

As the ex vivo environment is significantly different from the MSC niche, preservation of MSC potency in ex vivo expansion has become challenging. Shakouri-Motlagh et al. (2019) have proposed that the solubilized form of AM/CM can reproduce the natural environment of MSC in a feasible and reproducible way. AM and $\mathrm{CM}$ were solubilized through enzymatic digestion with pepsin, as it does not affect ECM bioactivity. As AM and $\mathrm{CM}$ have different compositions, the resulting solutions and environments had different bioactivities. According to their results, AME contains more protein, while CME is rich in GAGs. In addition, coatings produced from a $0.5-\mathrm{mg} / \mathrm{ml}$ AME induced the most proliferation in MSC, which was even more significant than the proliferation induced by Matrigel. Coatings based on AME were also able to maintain a much smaller MSC - more potent - and regulate its adipogenic and osteogenic differentiation. They concluded that AME is the most suitable substrate for preserving MSC potency.

\section{Osteogenesis}

The osteogenic effect of AME and CME is the least investigated characteristic of these extracts. Go et al. $(2016,2017)$ conducted two studies to explore the ability of AME and CME to promote the osteogenic differentiation of osteoblast-like cells (MG-63). According to their results, although both of these extracts contain osteogenic-related growth factors, CME stimulates osteogenic differentiation more than AME (Go et al., 2017). This phenomenon is due to the presence of EGF in AM and its downregulatory effect on osteogenic differentiation of stem cells. However, modification of AME with EGFR inhibitors results in the modulation of osteogenic efficiency and paves the way for regulating bone density or calcification.

\section{HYDROGEL BASED ON AMNIOTIC MEMBRANE}

In many cases, fresh, freeze-dried, or cryopreserved AM sheets are used for various clinical applications. However, they are associated with some challenges, such as the difficulty of handling without folding or tearing it before placing it on the injury site and its fixation on the injury site for a prolonged period (sutures, glue, or additional bandaging). Aside from AME, recently, a new strategy has been developed to eliminate these challenges by employing hydrogels based on AM. These hydrogels are usually formed by digesting the dAM with pepsin or other methods (based on AME formation) to integrate the benefits of the 
A

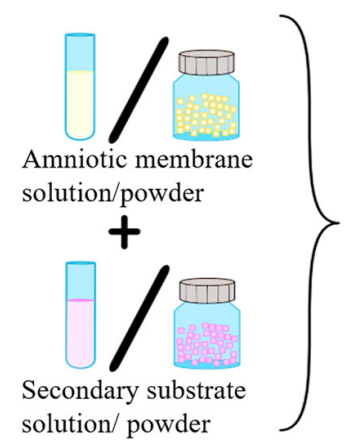

C

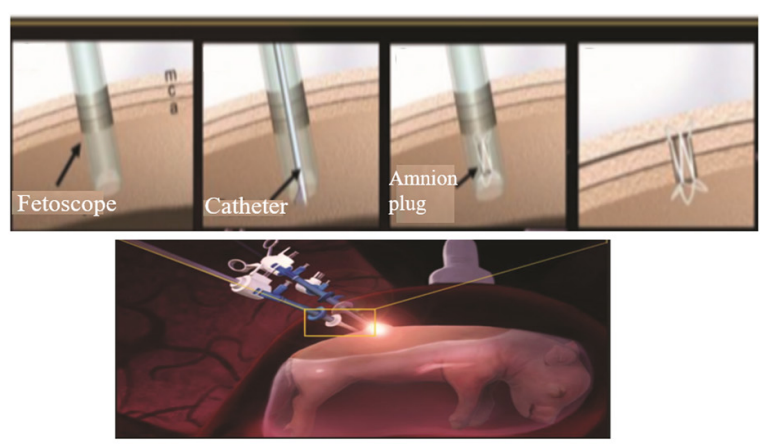

B

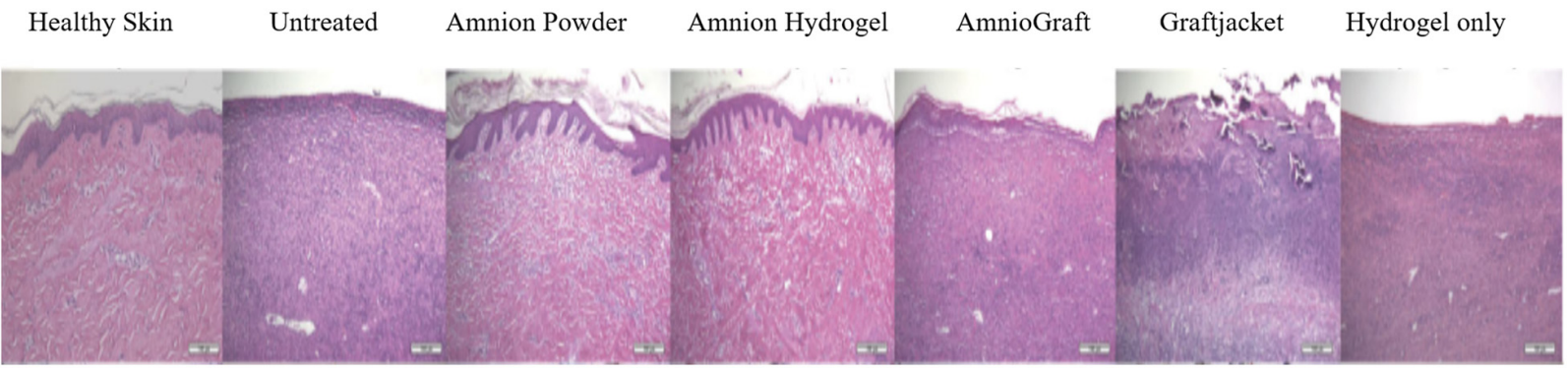

FIGURE 5 | (A) Schematic representation of the preparation of AM hydrogel alone or in combination with a secondary substrate. (B) Histological images with H\&E staining. Comparison of the efficiency of AM powder/hydrogel with commercially available products and other control groups. Skin treated with AM hydrogel and AM powder were very similar to the healthy skin [reproduced with permission from Tseng, 2016. Copyright 2019 Wiley]. (C) Placement of the AMED in the injured site of the fetal membrane by minimally invasive fetoscopic surgery [reproduced with permission from Lee et al., 2018. Copyright 2018 Wiley].

hydrogel structure with the growth factors and nutrients of the AM (Figure 5A). The produced hydrogel, which can be prepared alone or in combination with carriers for improved biological, mechanical, or gelation properties, has similar properties as collagen and fibrin (Murphy et al., 2017). The summary of the studies based on AM hydrogels is provided in Table 4.

One of the pioneers in this field is Hussin et al. (2011), with their 3D scaffold for cartilage TE applications. This scaffold was composed of AM and fibrin and two biodegradable and biocompatible materials and had a similar structure to hyaline cartilage. The results of this study show that this structure not only secreted cartilage-specific ECM and GAGs but also preserved cellular phenotype and had a suitable biodegradation rate (full, partial degradation at day 30). Another study has shown that AM-based hydrogels could have the required mechanical properties essential for articular cartilage TE. In the study conducted by Toniato et al. (2019), a hybrid hydrogel based on dAM and chitosan $(\mathrm{Ch})$ has been developed with high swelling capacity (ranged between $333 \pm 19 \%$ and $368 \pm 28 \%$ ) and elastic modulus (Mean of approximately $80 \mathrm{kPa}$ ).

AM-based hydrogels have also been applied for wound healing. In one study, Murphy et al. (2017) utilized UV crosslinked HA hydrogel as a carrier for AME to evaluate its efficiency in a full-thickness murine wound model. This easy-to-apply construct conformed the wound shape and depth after UV exposure and had started to degrade by day 7 after application. According to their data, HA-AME hydrogel accelerated wound closure approximately by $3 \%$ compared to HA-treated and untreated wounds through increased epithelialization and decreased contraction. Another interesting outcome of their study was that HA-AME-treated wounds had an overall smaller average vessel area in comparison with HA-treated wounds and untreated wounds. Following this study, Murphy et al. conducted another experiment to evaluate the influence of HA-AME over AM powder, AmnioGraft, and HA hydrogel on a full-thickness porcine skin wound model (Tseng, 2016). According to their data, HA-AME and AM powder both better stabilized the wound at days 4 and 7 in comparison with other treatments. Like the former outcomes, HA-AME, and this time AM powder, which were much easier to handle compared to other products, resulted in rapid wound closure rates with the formation of mature epidermis and dermis similar to healthy skin (Figure 5B).

Rahman et al. (2019) have conducted another study based on AM hydrogels for the development of a cost-effective and straightforward wound dressing for burn healing. Their hydrogel is a composition of AM and aloe vera (AV), which has widely been applied for burn healing. Based on their outcomes, this hydrogel had no cytotoxicity, and no edema or erythema was observed after its application for 7 days. According to their in vivo study, $A M$ had lower inflammation (even lower than the AM+AVtreated group) and scar formation. On the other hand, the $\mathrm{AM}+\mathrm{AV}$-treated group had a similar healing velocity to AM but with a higher epithelialization rate (on day 30). Another wound dressing for burns based on AM has been developed by Rana et al. (2020). This hydrogel was formed by the addition of a solution based on AM and collagen powder to the gelling agent (CMC$\mathrm{Na}$ ) and utilized in combination of a chitosan/collagen-blended 
TABLE 4 | Summary of studies based on AM hydrogels.

\begin{tabular}{|c|c|c|c|c|c|}
\hline Author, year & $\begin{array}{l}\text { Therapeutic } \\
\text { goal }\end{array}$ & $\begin{array}{l}\text { Experimental settings } \\
\text { (target tissue/cells) }\end{array}$ & $\begin{array}{l}\text { Secondary } \\
\text { biomaterial }\end{array}$ & Conclusion & References \\
\hline Hussin, 2011 & Cartilage TE & $\begin{array}{l}\text { In vitro } \\
\text { (primary chondrocytes) }\end{array}$ & Fibrinogen & $\begin{array}{l}\text { The hydrogel-based on AM and fibrin not only secretes } \\
\text { cartilage-specific ECM and has significant amounts of GAGs } \\
\text { but also preserves cellular phenotype and has a reasonable } \\
\text { biodegradation rate }\end{array}$ & $\begin{array}{l}\text { Hussin et al., } \\
2011\end{array}$ \\
\hline Ryzhuka, 2017 & $\begin{array}{l}\text { Cell delivery } \\
\text { and } \mathrm{TE}\end{array}$ & $\begin{array}{l}\text { In vitro and in vivo } \\
\text { (PMSCs, Sprague } \\
\text { Dawley rat) }\end{array}$ & - & $\begin{array}{l}\text { AM hydrogel supports cellular growth and maintains the } \\
\text { normal morphology and physiology of the embedded cells } \\
\text { and does not induce any inflammation }\end{array}$ & $\begin{array}{l}\text { Ryzhuk et al., } \\
2018\end{array}$ \\
\hline Murphy, 2017 & Wound healing & $\begin{array}{l}\text { In vitro and in vivo } \\
\text { (human dermal fibroblast } \\
\text { and keratinocyte, mice) }\end{array}$ & $\mathrm{HA}$ & $\begin{array}{l}\text { HA-AME hydrogel accelerates wound closure through } \\
\text { increasing epithelialization and decreasing contraction and } \\
\text { results in smaller average vessel areas }\end{array}$ & $\begin{array}{l}\text { Murphy et al., } \\
2017\end{array}$ \\
\hline Lee, 2018 & $\begin{array}{l}\text { Fetal membrane } \\
\text { healing }\end{array}$ & $\begin{array}{l}\text { In vivo } \\
\text { (pregnant miniature swine) }\end{array}$ & PCL framework & $\begin{array}{l}\text { AM gel successfully seals the defect site in the fetal } \\
\text { membrane and stop AF leakage }\end{array}$ & Lee et al., 2018 \\
\hline Murphy, 2019 & Wound healing & $\begin{array}{l}\text { In vivo } \\
\text { (pig) }\end{array}$ & $\mathrm{HA}$ & $\begin{array}{l}\text { HA-AME and AM powder both better stabilize the wound in } \\
\text { comparison with other treatments }\end{array}$ & Tseng, 2016 \\
\hline Toniato, 2019 & $\begin{array}{l}\text { Articular cartilage } \\
\text { TE }\end{array}$ & In vitro & Chitosan & $\begin{array}{l}\text { Hybrid hydrogel based on dAM and } \mathrm{Ch} \text { has the high swelling } \\
\text { capacity and elastic modulus }\end{array}$ & $\begin{array}{l}\text { Toniato et al., } \\
2019\end{array}$ \\
\hline Rahman, 2019 & $\begin{array}{l}\text { Burn wound } \\
\text { healing }\end{array}$ & $\begin{array}{l}\text { In vitro and in vivo (HaCaT, } \\
\text { HFF1, Wistar rats) }\end{array}$ & Aloe vera & $\begin{array}{l}\text { Wound dressing based on AM and AV accelerated wound } \\
\text { closure with minimum scar formation }\end{array}$ & $\begin{array}{l}\text { Rahman et al., } \\
2019\end{array}$ \\
\hline Henry, 2019 & $\begin{array}{l}\text { Post-Ml tissue } \\
\text { repair }\end{array}$ & $\begin{array}{l}\text { In vitro and in vivo (BAECs, } \\
\text { rat) }\end{array}$ & & $\begin{array}{l}\text { Injectable and thermoresponsive AM hydrogel improves } \\
\text { cardiac contractility and decreases fibrosis }\end{array}$ & $\begin{array}{l}\text { Henry et al., } \\
2020\end{array}$ \\
\hline Rana, 2020 & Burn healing & $\begin{array}{l}\text { In vitro and in vivo (RBC, } \\
\text { Wistar rat) }\end{array}$ & Collagen & $\begin{array}{l}\text { Hydrogel based on AM and collagen increases the rate of } \\
\text { wound healing mainly when it is utilized with a wound } \\
\text { dressing membrane }\end{array}$ & $\begin{array}{l}\text { Rana et al., } \\
2020\end{array}$ \\
\hline Lei, 2020 & Vascular graft & $\begin{array}{l}\text { In vitro and in vivo (HUVEC, } \\
\mathrm{RBC}, \text { New Zealand rabbit) }\end{array}$ & AlgSr/PAM & $\begin{array}{l}\text { This graft is resistance to enzymatic degradation and } \\
\text { possesses anti-calcification effect, activates platelet and } \\
\text { hemolysis, and enhances vascular remodeling and repair }\end{array}$ & Lei et al., 2020 \\
\hline Peng, 2020 & Vascular graft & $\begin{array}{l}\text { In vitro and in vivo (HUVECs, } \\
\text { HASMCs, New Zealand } \\
\text { rabbits }\end{array}$ & ADA/REDV & $\begin{array}{l}\text { This graft has enhanced mechanical strength and resistance } \\
\text { to enzymic degradation. It accelerates endothelialization, and } \\
\text { the addition of REDV to this structure stimulates natural } \\
\text { anticoagulant substances on naturally derived blood vessels. }\end{array}$ & $\begin{array}{l}\text { Peng et al., } \\
2020\end{array}$ \\
\hline
\end{tabular}

membrane or alone. According to their data, this biocompatible hydrogel resulted in rapid wound healing in a rat model with complete re-epithelialization and wound contraction.

Recently, AM-based hydrogels have been employed for the treatment of cardiovascular diseases. For instance, Henry et al. (2020) developed an injectable, thermoresponsive AM hydrogel to improve cardiac regeneration after myocardial infarction (MI). Using ultrasound-guided injection, they administrated AM hydrogel into rat MI hearts and evaluated its effect in comparison with PBS. Based on their data, this hydrogel significantly improved cardiac contractility and decreased fibrosis $(p<0.05)$. In another study, a dAM hydrogel modified with polyacrylamide-alginate (AlgSr/PAM) was utilized as a vascular graft in a rabbit model (Lei et al., 2020). This thermosensitive construct had high mechanical strength and bioactivity in addition to low swelling ratio. According to Lei et al., this graft showed resistance to enzymatic degradation and possessed an anti-calcification effect. Moreover, while it inhibited platelet activation and hemolysis, this graft enhanced the adhesion and expansion of endothelial cells as well as vascular remodeling and repair. In a similar experiment, Peng et al. (2020) used D-double-cross-linked decellularized AM hydrogel grafted with REDV(ArgGlu-AspVal) polypeptides which showed excellent mechanical strength and resistance to enzymatic degradation and inhibited hemolysis and coagulation (similar characteristics to the vascular graft developed by Lei et al.). Also, the addition of REDV to this structure stimulated natural anticoagulant substances on naturally derived blood vessels.

Amniotic membrane based hydrogel has also been utilized as a vehicle for cell delivery (Ryzhuk et al., 2018). In this experiment, Ryzhuka et al. developed an AM-ECM hydrogel via pepsin digestion of $\mathrm{dAM}$ and compared its effect to conventional collagen and fibrin hydrogel matrices. Based on their data, AM hydrogel gelation time is longer than fibrin gel and shorter than collagen. Their in vitro assessment shows the ability of AM-based hydrogel to support the cellular growth and high rates of cellular propagation. According to their results, AM-ECM is a biocompatible hydrogel that supports the natural morphology and physiology of a variety of stem cells. Besides, no tissue inflammation and immune cell activation were observed in their in vivo assessment on the Sprague Dawley rat model.

Another interesting application of AM hydrogel is actually to restore AM defects during pregnancy (Lee et al., 2018). This iatrogenic preterm premature rupture of the fetal membranes results in premature births and requires external intervention to stop amniotic fluid (AF) leakage. Lee et al. have developed a 3D-printed construct, which is called biocompatible amnionanalogous medical device (AMED), consisting of a PCL 
framework and dAM hydrogel to seal the defect site and preserve fetal survival (Figure 5C). To do this, dAM gel was injected in the AMED with a syringe and became cross-linked (after $30 \mathrm{~min}$ at $37^{\circ} \mathrm{C}$ ) and ready for application at the injury site. According to their results, it was possible to deliver this device through a fetoscope-sized catheter in $33.62 \pm 11.36 \mathrm{~s}$ (10.26 times faster than amniotic graft transplantation). Following that, this gel successfully sealed the defect site in all animals (pregnant miniature swine), and they recovered entirely after surgery and maintained a healthy condition until the end of the pregnancy.

\section{DISCUSSION}

The amniotic membrane contains many proteins and growth factors and, as a result, possesses interesting properties and structure. This low immunogen and biologically viable structure is easily accessible and has a reasonable price. These characteristics have made AM a popular choice for medical purposes. Its application in ophthalmology and skin care has a long history. Due to its desirable results, nowadays, there are commercially available AM products for clinical use. Additionally, although it has relatively poor mechanical properties, its utilization for bone and cartilage regeneration and internal surgeries is developing as a result of recent modifications to its structure.

With growing interest in $\mathrm{AM}$ applications in $\mathrm{TE}$ and regenerative medicine, some modifications have been made to improve its properties with the addition of other biological or synthetic materials. In this review, we have categorized and described these modifications and their final effect on the AM structure. Based on our research, these modifications can be categorized as composites based on AM, AME, and hydrogels based on AM. Composites based on AM are consist of an amniotic layer, which is (1) modified by a coating of particles or electrospun or casted layers, (2) applied as a coating over another structure, or (3) applied as particles to enhance the biological properties of another material. For instance, the AM antibacterial effect has been improved by the addition of silver nanoparticles and Calvanin A, its adhesion capacity has been regulated by insertion of halofuginone (alone or with chitosan), and its biocompatibility has been specialized by addition of tissue-specific ECM. Additionally, its wound

\section{REFERENCES}

Adamowicz, J., Juszczak, K., Bajek, A., Tworkiewicz, J., Nowacki, M., Marszalek, A., et al. (2012). Morphological and urodynamic evaluation of urinary bladder wall regeneration: muscles guarantee contraction but not proper functiona rat model research study. Transplant. Proc. 44, 1429-1434. doi: 10.1016/j. transproceed.2012.01.144

Adamowicz, J., Pasternak, I., Kloskowski, T., Gniadek, M., Van Breda, S. V., Buhl, M., et al. (2020). Development of a conductive biocomposite combining graphene and amniotic membrane for replacement of the neuronal network of tissue-engineered urinary bladder. Sci. Rep. 10, 1-15.

Adamowicz, J., Pokrywczyńska, M., Tworkiewicz, J., Kowalczyk, T., van Breda, S. V., Tyloch, D., et al. (2016). New amniotic membrane based biocomposite for future application in reconstructive urology. PLoS One 11:e0146012. doi: 10.1371/journal.pone. 0146012 healing features have been improved by the insertion of silk. Moreover, its mechanical properties and degeneration rate have been improved by adding a polymeric layer (such as electrospun PCL, PLCL) or gels (GelMA). On the other hand, AM can improve the inflammatory response, adhesion capacity, blood compatibility, and biocompatibility of other materials when it covers them or mixes with them to form a scaffold.

Additionally, AME, which is much easier to use and has the same effects of intact AM, can be formed into a hydrogel, which is easier to handle, store, and sterilize. AME has been especially useful in ophthalmology as it does not have the complications of surgeries, yet its best effect is when it is utilized in combination with AMT. In addition to the anti-inflammatory, antibacterial, anti-scarring, wound healing, and cardioprotective effects of AME, it is suitable for the regulation of stem cell differentiation and expansion. Hydrogels based on AM are mainly provided from the AME and, like AM and AME, posses interesting characteristics suitable for cartilage TE, vascular TE, cell delivery, cardiac tissue regeneration, and wound healing. It has even been applied as a structure to heal and seal fetal membrane injuries.

Based on our findings, although intact AM has always been a suitable option for many clinical and experimental studies, but by addition of extra modifications, it is possible to widen AM applications in the fields such as bone repair, cartilage TE, urinary bladder TE, oral defects, and many other areas that have been mentioned in this review. The growing number of studies that have applied AM with a modified structure highlights the need for further investigation of these structures and their importance. In this review, we have summarized and discussed these modifications.

\section{AUTHOR CONTRIBUTIONS}

All authors listed have made a substantial, direct and intellectual contribution to the work, and approved it for publication.

\section{FUNDING}

This work was supported by Shahid Beheshti University of Medical Sciences, grant number: 15679. of human amniotic membrane on silicone related capsule formation in rats. J. Plast. Surg. Hand Surg. 54, 284-289. doi: 10.1080/2000656x.2020.1766476

Alamouti, M. A., Shayan, N., Momeni, M., Koohkan, A., Hajizadeh-Saffar, E., Nouri, M., et al. (2019). Investigation on the safety of amniotic membrane extracts in improving diabetic foot ulcers (phase 1 clinical trial study). Iran. J. Diab. Metabol. 18, 0-0.

Anisuzzaman, M. M., Khan, S. R., Khan, M. T. I., Ahmed, A. U., Wahiduzzaman, M., and Sarkar, M. A. A. (2018). Evaluation of epithelization when amniotic membrane use as a biologic dressing in oral cavity. Update Dent. College J. 8, 36-40. doi: 10.3329/updcj.v8i1.38410

Arasteh, S., Khanjani, S., Golshahi, H., Mobini, S., Jahed, M. T., Heidari-Vala, H., et al. (2020). Efficient wound healing using a synthetic nanofibrous bilayer skin substitute in murine model. J. Surg. Res. 245, 31-44. doi: 10.1016/j.jss.2019. 07.017 
Asl, N. S., Nejat, F., Mohammadi, P., Nekoukar, A., Hesam, S., Ebrahimi, M., et al. (2019). Amniotic membrane extract eye drop promotes limbal stem cell proliferation and corneal epithelium healing. Cell J. 20, 459.

Aslani, S., Kabiri, M., Kehtari, M., and Hanaee-Ahvaz, H. (2019). Vascular tissue engineering: fabrication and characterization of acetylsalicylic acid-loaded electrospun scaffolds coated with amniotic membrane lysate. J. Cell. Physiol. 234, 16080-16096. doi: 10.1002/jcp.28266

Attinger, C., and Wolcott, R. (2012). Clinically addressing biofilm in chronic wounds. Adv. Wound Care 1, 127-132. doi: 10.1089/wound.2011.0333

Aziz, N. A., Nazly, H., and Norimah, Y. (2017). Human Amniotic Membrane: Basic Science and Clinical Application. Singapore: World Scientific.

Baradaran-Rafii, A., Asl, N. S., Ebrahimi, M., Jabbehdari, S., Bamdad, S., Roshandel, D., et al. (2018). The role of amniotic membrane extract eye drop (AMEED) in in vivo cultivation of limbal stem cells. Ocular Surf. 16, 146-153. doi: 10.1016/j.jtos.2017.11.001

Barski, D., Gerullis, H., Ecke, T., Yang, J., Varga, G., Boros, M., et al. (2017). Bladder reconstruction with human amniotic membrane in a xenograft rat model: a preclinical study. Int. J. Med. Sci. 14, 310. doi: 10.7150/ijms. 18127

Baylis, O., Figueiredo, F., Henein, C., Lako, M., and Ahmad, S. (2011). 13 years of cultured limbal epithelial cell therapy: a review of the outcomes. J. Cell. Biochem. 112, 993-1002. doi: 10.1002/jcb.23028

Becker, M., Maring, J., Schneider, M., Herrera Martin, A., Seifert, M., Klein, O., et al. (2018). Towards a novel patch material for cardiac applications: tissue-specific extracellular matrix introduces essential key features to decellularized amniotic membrane. Int. J. Mol. Sci. 19, 1032. doi: 10.3390/ijms19041032

Branton, M. H., and Kopp, J. B. (1999). TGF- $\beta$ and fibrosis. Microbes Infect. 1, 1349-1365.

Brown, G. L., Nanney, L. B., Griffen, J., Cramer, A. B., Yancey, J. M., Curtsinger, L. J. III, et al. (1989). Enhancement of wound healing by topical treatment with epidermal growth factor. New Engl. J. Med. 321, 76-79. doi: 10.1056/ nejm198907133210203

Brücher, V. C., Eter, N., and Uhlig, C. E. (2020). Results of resorbable and running sutured amniotic multilayers in sterile deep corneal ulcers and perforations. Cornea 39, 952-956.

Cai, M., Zhang, J., Guan, L., and Zhao, M. (2015). Novel implantable composite biomaterial by fibrin glue and amniotic membrane for ocular surface reconstruction. J. Mater. Sci. Mater. Med. 26, 149.

Castellanos, G., Bernabe-Garcia, A., Moraleda, J. M., and Nicolas, F. J. (2017). Amniotic membrane application for the healing of chronic wounds and ulcers. Placenta 59, 146-153. doi: 10.1016/j.placenta.2017.04.005

Chang, D., Seo, S., and Hong, C. (2002). The effect of amniotic membrane extract on the expression of iNOS mRNA and generation of NO in HaCaT cell by ultraviolet B irradiation. Photodermatol. Photoimmunol. Photomed. 18, 280-286. doi: 10.1034/j.1600-0781.2002.02752.x

Chen, B., Jones, R. R., Mi, S., Foster, J., Alcock, S. G., Hamley, I. W., et al. (2012). The mechanical properties of amniotic membrane influence its effect as a biomaterial for ocular surface repair. Soft Matter 8, 8379-8387. doi: 10.1039/ c2sm26175h

Choi, J. A., Choi, J.-S., and Joo, C.-K. (2011). Effects of amniotic membrane suspension in the rat alkali burn model. Mol. Vision 17, 404.

Choi, J. A., Jin, H. J., Jung, S., Yang, E., Choi, J. S., Chung, S. H., et al. (2009). Effects of amniotic membrane suspension in human corneal wound healing in vitro. Mol. Vision 15, 2230.

Choi, Y. K., Din, F. U., Kim, D. W., Kim, Y. I., Kim, J. O., Ku, S. K., et al. (2014). Amniotic membrane extract-loaded double-layered wound dressing: evaluation of gel properties and wound healing. Drug Dev. Ind. Pharm. 40, 852-859. doi: 10.3109/03639045.2013.788015

Chopra, A., and Thomas, B. S. (2013). Amniotic membrane: a novel material for regeneration and repair. J. Biomimet. Biomater. Tissue Eng. 18, 1-8.

Chuck, R. S., Graff, J. M., Bryant, M. R., and Sweet, P. M. (2004). Biomechanical characterization of human amniotic membrane preparations for ocular surface reconstruction. Ophthal. Res. 36, 341-348. doi: 10.1159/000081637

De Luca, M., Pellegrini, G., and Green, H. (2006). Regeneration of squamous epithelia from stem cells of cultured grafts. Future Med. 1, 45-57. doi: 10.2217/ 17460751.1.1.45

Dewey, M. J., Johnson, E. M., Slater, S. T., Milner, D. J., Wheeler, M. B., and Harley, B. A. C. (2020). Mineralized collagen scaffolds fabricated with amniotic membrane matrix increase osteogenesis under inflammatory conditions. Regen. Biomater. 7, 247-258. doi: 10.1093/rb/rbaa005

Dudok, D. V., Nagdee, I., Cheung, K., Liu, H., Vedovelli, L., Ghinelli, E., et al. (2015). Effects of amniotic membrane extract on primary human corneal epithelial and limbal cells. Clin. Exp. Ophthalmol. 43, 443-448. doi: 10.1111/ ceo. 12480

Ehredt, D. J. Jr., Zulauf, E. E., min Kim, H., and Connors, J. (2019). Cryopreserved amniotic membrane and autogenous adipose tissue as an interpositional spacer after resection of a cubonavicular coalition: a case report and review of the literature. J. Foot Ankle Surg. 59, 173-177. doi: 10.1053/j.jfas.2019. 03.024

Espana, E. M., Kawakita, T., Liu, C. Y., and Tseng, S. C. G. (2004). CD34 expression by cultured human keratocytes is downregulated during myofibroblast differentiation induced by TGF- $\beta 1$. Invest. Ophthalmol. Vis. Sci. 45, 2985-2991. doi: 10.1167/iovs.04-0201

Fairbairn, N., Randolph, M., and Redmond, R. (2014). The clinical applications of human amnion in plastic surgery. J. Plast. Reconstruct. Aesthetic Surg. 67, 662-675. doi: 10.1016/j.bjps.2014.01.031

Fard, M., Akhavan-Tavakoli, M., Khanjani, S., Zare, S., Edalatkhah, H., Arasteh, S., et al. (2018). Bilayer amniotic membrane/nano-fibrous fibroin scaffold promotes differentiation capability of menstrual blood stem cells into keratinocyte-like cells. Molecular biotechnology 60, 100-110. doi: 10.1007/ s12033-017-0049-0

Farhadihosseinabadi, B., Farahani, M., Tayebi, T., Jafari, A., Biniazan, F., Modaresifar, K., et al. (2018). Amniotic membrane and its epithelial and mesenchymal stem cells as an appropriate source for skin tissue engineering and regenerative medicine. Artif. Cells Nanomed. Biotechnol. 46(suppl. 2), 431-440. doi: 10.1080/21691401.2018.1458730

Faridvand, Y., Haddadi, P., Vahedian, V., Nozari, S., Nejabati, H. R., Pezeshkian, M., et al. (2020). Human amnion membrane proteins prevent doxorubicininduced oxidative stress injury and apoptosis in rat $\mathrm{H} 9 \mathrm{c} 2$ cardiomyocytes. Cardiovasc. Toxicol. 20, 370-379. doi: 10.1007/s12012-020-09564-8

Faridvand, Y., Nozari, S., Atashkhoei, S., Nouri, M., and Jodati, A. (2018). Amniotic membrane extracted proteins protect H9c2 cardiomyoblasts against hypoxiainduced apoptosis by modulating oxidative stress. Biochem. Biophys. Res. Commun. 503, 1335-1341. doi: 10.1016/j.bbrc.2018.07.045

Faridvand, Y., Nozari, S., Vahedian, V., Safaie, N., Pezeshkian, M., Haddadi, P., et al. (2019). Nrf2 activation and down-regulation of HMGB1 and MyD88 expression by amnion membrane extracts in response to the hypoxia-induced injury in cardiac H9c2 cells. Biomed. Pharmacother. 109, 360-368. doi: 10.1016/j.biopha. 2018.10.035

Farzan, R., Moeinian, M., Abdollahi, A., Jahangard-Rafsanjani, Z., Alipour, A., Ebrahimi, M., et al. (2018). Effects of amniotic membrane extract and deferoxamine on angiogenesis in wound healing: an in vivo model. J. Wound Care 27(Suppl. 6), S26-S32.

Fénelon, M., Catros, S., and Fricain, J. (2018). What is the benefit of using amniotic membrane in oral surgery? A comprehensive review of clinical studies. Clin. Oral Invest. 22, 1881-1891. doi: 10.1007/s00784-018-2457-3

Gheorghe, A., Pop, M., Burcea, M., and Serban, M. (2016). New clinical application of amniotic membrane transplant for ocular surface disease. J. Med. Life 9, 177.

Gholipourmalekabadi, M., Farhadihosseinabadi, B., Faraji, M., and Nourani, M. R. (2019a). How preparation and preservation procedures affect the properties of amniotic membrane? How safe are the procedures? Burns 46, 1254-1271. doi: 10.1016/j.burns.2019.07.005

Gholipourmalekabadi, M., Khosravimelal, S., Nokhbedehghan, Z., Sameni, M., Jajarmi, V., Urbanska, A. M., et al. (2019b). Modulation of hypertrophic scar formation using amniotic membrane/electrospun silk fibroin bilayer membrane in a rabbit ear model. ACS Biomater. Sci. Eng. 5, 1487-1496. doi: 10.1021/ acsbiomaterials. $8 \mathrm{~b} 01521$

Gholipourmalekabadi, M., Samadikuchaksaraei, A., Seifalian, A. M., Urbanska, A. M., Ghanbarian, H., Hardy, J. G., et al. (2018a). Silk fibroin/amniotic membrane 3D bi-layered artificial skin. Biomed. Mater. 13, 035003. doi: 10. 1088/1748-605x/aa999b

Gholipourmalekabadi, M., Seifalian, A. M., Urbanska, A. M., Omrani, M. D., Hardy, J. G., Madjd, Z., et al. (2018b). 3D protein-based bilayer artificial skin for the guided scarless healing of third-degree burn wounds in vivo. Biomacromolecules 19, 2409-2422. doi: 10.1021/acs.biomac.7b01807 
Gicquel, J. J., Dua, H. S., Brodie, A., Mohammed, I., Suleman, H., Lazutina, E., et al. (2009). Epidermal growth factor variations in amniotic membrane used for ex vivo tissue constructs. Tissue Eng. Part A 15, 1919-1927. doi: 10.1089/ ten.tea.2008.0432

Go, Y. Y., Kim, S. E., Cho, G. J., Chae, S. W., and Song, J. J. (2016). Promotion of osteogenic differentiation by amnion/chorion membrane extracts. J. Appl. Biomater. Funct. Mater. 14, 171-180.

Go, Y. Y., Kim, S. E., Cho, G. J., Chae, S. W., and Song, J. J. (2017). Differential effects of amnion and chorion membrane extracts on osteoblast-like cells due to the different growth factor composition of the extracts. PLoS One 12:e0182716. doi: 10.1371/journal.pone.0182716

Gregory, C. A., Reyes, E., Whitney, M. J., and Spees, J. L. (2006). Enhanced engraftment of mesenchymal stem cells in a cutaneous wound model by culture in allogenic species-specific serum and administration in fibrin constructs. Stem Cells 24, 2232-2243. doi: 10.1634/stemcells.2005-0612

Gremare, A., Jean-Gilles, S., Musqui, P., Magnan, L., Torres, Y., Fenelon, M., et al. (2019). Cartography of the mechanical properties of the human amniotic membrane. J. Mech. Behav. Biomed. Mater. 99, 18-26. doi: 10.1016/j.jmbbm. 2019.07.007

He, H., Li, W., Chen, S. Y., Zhang, S., Chen, Y. T., Hayashida, Y., et al. (2008). Suppression of activation and induction of apoptosis in RAW264. 7 cells by amniotic membrane extract. Invest. Ophthalmol. Vis. Sci. 49, 4468-4475. doi: 10.1167/iovs.08-1781

He, H., Li, W., Tseng, D. Y., Zhang, S., Chen, S. Y., Day, A. J., et al. (2009). Biochemical characterization and function of complexes formed by hyaluronan and the heavy chains of inter- $\alpha$-inhibitor (HC - HA) purified from extracts of human amniotic membrane. J. Biol. Chem. 284, 20136-20146. doi: 10.1074/jbc. m109.021881

Henry, J. J. D., Delrosario, L., Fang, J., Wong, S. Y., Fang, Q., Sievers, R., et al. (2020). Development of injectable amniotic membrane matrix for postmyocardial infarction tissue repair. Adv. Healthcare Mater. 9, 1900544. doi: 10.1002/adhm.201900544

Horn, A., Saller, J., Cuttica, D., and Neufeld, S. (2019). Review of use of amniotic membrane allograft in total ankle replacements. Foot Ankle Orthopaedics 4, 2473011419 S00222.

Hortensius, R. A., Ebens, J. H., Dewey, M. J., and Harley, B. A. C. (2018). Incorporation of the amniotic membrane as an immunomodulatory design element in collagen scaffolds for tendon repair. ACS Biomater. Sci. Eng. 4, 4367-4377. doi: 10.1021/acsbiomaterials.8b01154

Hortensius, R. A., Ebens, J. H., and Harley, B. A. (2016). Immunomodulatory effects of amniotic membrane matrix incorporated into collagen scaffolds. J. Biomed. Mater. Res. Part A 104, 1332-1342. doi: 10.1002/jbm.a.35663

Hossain, M. L., Rahman, M. A., Siddika, A., Adnan, M., Rahman, H., Diba, F., et al. (2020). Medicine, burn and wound healing using radiation sterilized human amniotic membrane and Centella asiatica derived gel: a review. Regen. Eng. Transl. Med. 6, 347-357.

Hussin, I., Pingguan-Murphy, B., and Osman, S. (2011). "The fabrication of human amniotic membrane based hydrogel for cartilage tissue engineering applications: a preliminary study," in Proceesings of the 5th Kuala Lumpur International Conference on Biomedical Engineering 2011 (Berlin: Springer).

Ilic, D., Vicovac, L., Nikolic, M., and Lazic Ilic, E. (2016). Human amniotic membrane grafts in therapy of chronic non-healing wounds. Br. Med. Bull. 117, 59-67. doi: 10.1093/bmb/ldv053

Inci, I., Norouz Dizaji, A., Ozel, C., Morali, U., Dogan Guzel, F., and Avci, H. (2020). Decellularized inner body membranes for tissue engineering: a review. J. Biomater. Sci. Polym. Edition 31, 1287-1368. doi: 10.1080/09205063.2020. 1751523

Iravani, K., Mehravar, S., Bahador, M., and Azarpira, N. (2020). The healing effect of amniotic membrane in laryngeal defects in rabbit model. Laryngoscope doi: 10.1002/lary.28745 [Epub ahead of print].

Islam, R., Rahman, M. S., Asaduzzaman, S. M., and Rahman, M. S. (2015). Properties and therapeutic potential of human amniotic membrane. Asian J. Dermatol. 7, 1-12. doi: 10.3923/ajd.2015.1.12

Jafari, A., Niknejad, H., Rezaei-Tavirani, M., D'Amico, C., and Zali, H. (2020). The biological mechanism involved in anticancer properties of amniotic membrane. Oncology reviews $14,429$.

Jiang, A., Li, C., Gao, Y., Zhang, M., Hu, J., Kuang, W., et al. (2006). In vivo and in vitro inhibitory effect of amniotic extraction on neovascularization. Cornea 25, S36-S40.
Jiang, T., Wang, G., Xu, S., and Zhao, H. (2007). “A novel intravascular stents covered with human amniotic membrane," in Proceedings of the 2007 IEEE/ICME International Conference on Complex Medical Engineering (Beijing: IEEE).

Jorge, L. F., Francisco, J. C., Bergonse, N., Baena, C., Carvalho, K. A. T., Abdelwahid, E., et al. (2018). Tracheal repair with acellular human amniotic membrane in a rabbit model. J. Tissue Eng. Regen. Med. 12, e1525-e1530.

Kane, C. J. M., Hebda, P. A., Mansbridge, J. N., and Hanawalt, P. C. (1991). Direct evidence for spatial and temporal regulation of transforming growth factor $\beta 1$ expression during cutaneous wound healing. J. Cell. Physiol. 148, 157-173. doi: $10.1002 /$ jcp. 1041480119

Kang, M., Choi, S., and Lee, A.-R. C. (2013). Effect of freeze dried bovine amniotic membrane extract on full thickness wound healing. Arch. Pharm. Res. 36, 472-478. doi: 10.1007/s12272-013-0079-5

Kaup, M., Redbrake, C., Plange, N., Arend, K. O., and Remky, A. (2008). Amniotic membrane transplantation in severe ocular surface disorders. Eur. J. Ophthalmol. 18, 691-694. doi: 10.1177/112067210801800505

Khosravimelal, S., Momeni, M., Gholipur, M., Kundu, S. C., and Gholipourmalekabadi, M. (2020). Protocols for decellularization of human amniotic membrane. Methods Cell Biol. 157, 37-47. doi: 10.1016/bs.mcb.2019.11.004

Kim, J. C., and Tseng, S. (1995). Transplantation of preserved human amniotic membrane for surface reconstruction in severely damaged rabbit corneas. Cornea 14, 473-484.

King, A. E., Paltoo, A., Kelly, R. W., Sallenave, J. M., Bocking, A. D., and Challis, J. R. G. (2007). Expression of natural antimicrobials by human placenta and fetal membranes. Placenta 28, 161-169. doi: 10.1016/j.placenta.2006.01.006

Kordić, R., Popović Suić, S., Jandroković, S., Kalauz, M., Kuzman, T., Škegro, I., et al. (2013). Application of the amniotic membrane extract (AMX) for the persistent epithelial defect (PED) of the cornea. Collegium Antropol. 37, $161-164$.

Kunert, K. S., Tisdale, A. S., and Gipson, I. K. (2002). Goblet cell numbers and epithelial proliferation in the conjunctiva of patients with dry eye syndrome treated with cyclosporine. Arch. Ophthalmol. 120, 330-337. doi: 10.1001/ archopht.120.3.330

Lacorzana, J. (2020). Amniotic membrane, clinical applications and tissue engineering. Review of its ophthalmic use. Arch. Soc. Española Oftalmol. 95, 15-23. doi: 10.1016/j.oftale.2019.09.008

Laranjeira, P., Duque, M., Vojtek, M., Inácio, M. J., Silva, I., Mamede, A. C., et al. (2018). Amniotic membrane extract differentially regulates human peripheral blood T cell subsets, monocyte subpopulations and myeloid dendritic cells. Cell Tissue Res. 373, 459-476. doi: 10.1007/s00441-018-2822-1

Lau, H. H., Jou, Q. B., Huang, W. C., and Su, T. H. (2020). Amniotic membrane graft in the management of complex vaginal mesh erosion. J. Clin. Med. 9, 356. doi: $10.3390 / \mathrm{jcm} 9020356$

Lee, H. N., Bernardo, R., Han, G. Y., Kim, G. Y., Kim, J. S., Jung, W. Y., et al. (2016). Human amniotic membrane extracts have anti-inflammatory effects on damaged human corneal epithelial cells in vitro. J. Hard Tissue Biol. 25, 282-287. doi: $10.2485 /$ jhtb.25.282

Lee, J. Y., Kim, H., Ha, D. H., Shin, J. C., Kim, A., Ko, H. S., et al. (2018). Amnionanalogous medical device for fetal membrane healing: a preclinical long-term study. Adv. Healthcare Mater. 7, 1800673. doi: 10.1002/adhm.201800673

Lei, X., Wu, Y., Peng, X., Zhao, Y., Zhou, X., and Yu, X. (2020). Research on alginate-polyacrylamide enhanced amnion hydrogel, a potential vascular substitute material. Mater. Sci. Eng. C 115, 111145. doi: 10.1016/j.msec.2020. 111145

Lewandrowski, K., Wise, D. L., Yaszemski, M. J., Gresser, J. D., Trantolo, D. J., and Altobelli, D. E. (2002). Tissue Engineering and Biodegradable Equivalents, Scientific and Clinical Applications. Boca Raton, FL: CRC Press.

Li, W., He, H., Chen, Y. T., Hayashida, Y., and Tseng, S. C. G. (2008). Reversal of myofibroblasts by amniotic membrane stromal extract. J. Cell. Physiol. 215, 657-664. doi: 10.1002/jcp.21345

Li, W., He, H., Kawakita, T., Espana, E. M., and Tseng, S. C. G. (2006). Amniotic membrane induces apoptosis of interferon- $\gamma$ activated macrophages in vitro. Exp. Eye Res. 82, 282-292. doi: 10.1016/j.exer.2005.06.022

Liang, L., Li, W., Ling, S., Sheha, H., Qiu, W., Li, C., et al. (2009). Amniotic membrane extraction solution for ocular chemical burns. Clin. Exp. Ophthalmol. 37, 855-863. doi: 10.1111/j.1442-9071.2009.02159.x 
Liang, X., Zhou, L., and Yan, J. (2019). Amniotic membrane for treating skin graft donor sites: a systematic review and meta-analysis. Burns 46, 621-629. doi: 10.1016/j.burns.2019.09.010

Litwiniuk, M., Radowicka, M., Krejner, A., and Grzela, T. (2017). The influence of amniotic membrane extracts on cell growth depends on the part of membrane and childbirth mode selected: a proof-of-concept study. J. Wound Care 26, 498-503. doi: 10.12968/jowc.2017.26.8.498

Litwiniuk, M., Radowicka, M., Krejner, A., Śladowska, A., and Grzela, T. (2018). Amount and distribution of selected biologically active factors in amniotic membrane depends on the part of amnion and mode of childbirth. Can we predict properties of amnion dressing? A proof-of-concept study. Central Eur. J. Immunol. 43, 97. doi: 10.5114/ceji.2017.69632

Liu, H., Zhou, Z., Lin, H., Wu, J., Ginn, B., Choi, J. S., et al. (2018). Synthetic nanofiber-reinforced amniotic membrane via interfacial bonding. ACS Appl. Mater. Interfaces 10, 14559-14569. doi: 10.1021/acsami.8b03087

Liu, J., Zou, H., Zeng, M., Huang, A. M., Chen, Y., Han, E., et al. (2020). Cytoprotective effect of amniotic membrane extracts on human corneal epithelial cells exposed to benzalkonium chloride in vitro. Ann. Eye Sci. 5, 11. doi: 10.21037/aes.2020.02.06

Mahbod, M., Shahhoseini, S., Khabazkhoob, M., Beheshtnejad, A. H., Bakhshandeh, H., Atyabi, F., et al. (2014). Amniotic membrane extract preparation: what is the best method? J. Ophthal. Vision Res. 9, 314.

Malhotra, C., and Jain, A. K. (2014). Human amniotic membrane transplantation: different modalities of its use in ophthalmology. World J. Transplant. 4, 111. doi: 10.5500/wjt.v4.i2.111

Mamede, A. C., and Botelho, M. F. (2015). Amniotic Membrane: Origin, Characterization and Medical Applications. Berlin: Springer.

Mamede, A. C., Carvalho, M. J., Abrantes, A. M., Laranjo, M., Maia, C. J., and Botelho, M. F. (2012). Amniotic membrane: from structure and functions to clinical applications. Cell 349, 447-458. doi: 10.1007/s00441-012-1424-6

Mandal, S. M., Khan, J., Mahata, D., Saha, S., Sengupta, J., Silva, O. N., et al. (2017). A self-assembled clavanin A-coated amniotic membrane scaffold for the prevention of biofilm formation by ocular surface fungal pathogens. Biofouling 33, 881-891. doi: 10.1080/08927014.2017.1383400

Mao, Y., Hoffman, T., Johnson, A., Duan-Arnold, Y., Danilkovitch, A., and Kohn, J. (2016). Human cryopreserved viable amniotic membrane inhibits the growth of bacteria associated with chronic wounds. J. Diab. Foot Comp. 8, 23-30.

Mermet, I., Pottier, N., Sainthillier, J. M., Malugani, C., Cairey-Remonnay, S., Maddens, S., et al. (2007). Use of amniotic membrane transplantation in the treatment of venous leg ulcers. Wound Repair Regen. 15, 459-464. doi: 10.1111/ j.1524-475x.2007.00252.x

Milan, P. B., Amini, N., Joghataei, M. T., Ebrahimi, L., Amoupour, M., Sarveazad, A., et al. (2020). Decellularized human amniotic membrane: from animal models to clinical trials. Methods 171, 11-19. doi: 10.1016/j.ymeth.2019.07.018

Mohan, R., Bajaj, A., and Gundappa, M. (2017). Human amnion membrane: potential applications in oral and periodontal field. J. Int. Soc. Prevent. Commun. Dent. 7, 15. doi: 10.4103/jispcd.jispcd_359_16

Murphy, S. V., Skardal, A., Nelson, R. A. Jr., Sunnon, K., Reid, T., Clouse, C., et al. (2019). Amnion membrane hydrogel and amnion membrane powder accelerate wound healing in a full thickness porcine skin wound model. Stem Cells Transl. Med. 9, 80-92. doi: 10.1002/sctm.19-0101

Murphy, S. V., Skardal, A., Song, L., Sutton, K., Haug, R., Mack, D. L., et al. (2017). Solubilized amnion membrane hyaluronic acid hydrogel accelerates full-thickness wound healing. Stem Cells Transl. Med. 6, 2020-2032. doi: 10. 1002/sctm.17-0053

Murri, M. S., Moshirfar, M., Birdsong, O. C., Ronquillo, Y. C., Ding, Y., and Hoopes, P. C. (2018). Amniotic membrane extract and eye drops: a review of literature and clinical application. Clin. Ophthalmol. 12, 1105. doi: 10.2147/ opth.s165553

Najibpour, N., Ahmed, M. A. A. H., Bananzadeh, A., Rezaianzadeh, A., Kermani, M. R., Gabash, K. M., et al. (2016). The effect of human amniotic membrane as a covering layer on propylene mesh in decrease of adhesion after laparotomy in the rabbit. Comp. Clin. Pathol. 25, 131-135. doi: 10.1007/s00580-015-2153-5

Nassif, J., Abbasi, S. A., Kechli, M. K., Boutary, S. S., Ghulmiyyah, L., Khalifeh, I., et al. (2016). Effect of the mode of application of cryopreserved human amniotic membrane on adhesion formation after abdomino-pelvic surgery in a mouse model. Front. Med. 3:10. doi: 10.3389/fmed.2016.00010
Nguyen, T. H., Paluck, S. J., McGahran, A. J., and Maynard, H. D. (2015). Poly (vinyl sulfonate) facilitates bFGF-induced cell proliferation. Biomacromolecules 16, 2684-2692. doi: 10.1021/acs.biomac.5b00557

Niknejad, H., Peirovi, H., Jorjani, M., Ahmadiani, A., Ghanavi, J., and Seifalian, A. M. (2008). Properties of the amniotic membrane for potential use in tissue engineering. Eur. Cells Mater. 15, 88-99. doi: 10.22203/ecm.v015a07

Norouzi, M., Shabani, I., Ahvaz, H. H., and Soleimani, M. (2015a). PLGA/gelatin hybrid nanofibrous scaffolds encapsulating EGF for skin regeneration. J. Biomed. Mater. Res. A 103, 2225-2235. doi: 10.1002/jbm.a.35355

Norouzi, M., Shabani, I., Atyabi, F., and Soleimani, M. (2015b). EGF-loaded nanofibrous scaffold for skin tissue engineering applications. Fibers Polym. 16, 782-787. doi: 10.1007/s12221-015-0782-6

Ogawa, K., Chen, F., Kuang, C., and Chen, Y. (2004). Suppression of matrix metalloproteinase- 9 transcription by transforming growth factor- $\beta$ is mediated by a nuclear factor- $\mathrm{B}$ site. Biochem. J. 381, 413-422. doi: 10.1042/bj2004 0058

Orman, S., Yol, S., Uzun, H., Ceyran, A. B., and Eyüboğlu, F. (2018). Effect of acellular amniotic membrane matrix patch on healing of cut surface after sleeve gastrectomy in rats. J. Invest. Surg. 33, 97-105. doi: 10.1080/08941939.2018. 1473902

Paolin, A., Cogliati, E., Trojan, D., Griffoni, C., Grassetto, A., Elbadawy, H. M., et al. (2016). Amniotic membranes in ophthalmology: long term data on transplantation outcomes. Cell Tissue Bank. 17, 51-58. doi: 10.1007/s10561015-9520-y

Papakonstantinou, E., Aletras, A. J., Roth, M., Tamm, M., and Karakiulakis, G. (2003). Hypoxia modulates the effects of transforming growth factor- $\beta$ isoforms on matrix-formation by primary human lung fibroblasts. Cytokine 24, 25-35. doi: 10.1016/s1043-4666(03)00253-9

Park, J. H., Kim, H. B., Ko, S. H., Kim, B. H., Lim, Y. S., Park, S. W., et al. (2020). Effects of amniotic membrane extract on the hyperplastic response of the middle ear mucosa in a bacterially-induced otitis media rat model: a preliminary study. Clin. Exp. Otorhinolaryngol. 13, 381-388. doi: 10.21053/ceo. 2019.01753

Peng, X., Wang, X., Cheng, C., Zhou, X., Gu, Z., Li, L., et al. (2020). Bioinspired, artificial, small-diameter vascular grafts with selective and rapid endothelialization based on an amniotic membrane-derived hydrogel. ACS Biomater. Sci. Eng. 6, 1603-1613. doi: 10.1021/acsbiomaterials.9b0 1493

Pflugfelder, S. C., De Paiva, C. S., Villarreal, A. L., and Stern, M. E. (2008). Effects of sequential artificial tear and cyclosporine emulsion therapy on conjunctival goblet cell density and transforming growth factor- $\beta 2$ production. Cornea 27 , 64-69. doi: 10.1097/ico.0b013e318158f6dc

Plummer, C. E. (2009). The use of amniotic membrane transplantation for ocular surface reconstruction: a review and series of 58 equine clinical cases (20022008). Vet. Ophthalmol. 12, 17-24. doi: 10.1111/j.1463-5224.2009.00741.x

Puyana, S., Ruiz, S., Elkbuli, A., Bernal, E., McKenney, M., Lim, R., et al. (2019). Using dehydrated amniotic membrane skin substitute in facial burns: is there outcome difference between adults versus pediatric patients. J. Craniofacial Surg. 31, e145-e147.

Rahman, S., Islam, R., Rana, M., Spitzhorn, L. S., Rahman, M. S., Adjaye, J., et al. (2019). Characterization of burn wound healing gel prepared from human amniotic membrane and Aloe vera extract. BMC Comp. Altern. Med. 19:115. doi: 10.1186/s12906-019-2525-5

Ramaesh, K., and Dhillon, B. (2003). Ex vivo expansion of corneal limbal epithelial/stem cells for corneal surface reconstruction. Eur. J. Ophthalmol. 13, 515-524. doi: 10.1177/112067210301300602

Ramakrishnan, R., Krishnan, L. K., Nair, R. P., and Kalliyana Krishnan, V. (2019). Reinforcement of amniotic membrane with fibrin coated poly-[Lactideco-Glycolide-co-Caprolactone] terpolymer containing silver nanoparticles for potential wound healing applications. Int. J. Polym. Mater. Polym. Biomater. 62, 1-10.

Ramesh, B., Chandrasekaran, J., Jeevankumar, S., Jacob, G., and Cherian, K. M. (2017). Hybrid amniotic membrane dressing with green silver nanoparticles as bioengineered skin for wounds and burns: a pilot studies. J. Biotechnol. Biomater. 7, 2.

Rana, M., Rahman, S., Ullah, A., Siddika, A., Hossain, L., Akhter, S., et al. (2020). Amnion and collagen-based blended hydrogel improves burn healing efficacy 
on rat skin wound model in presence of wound dressing biomembrane. Bio Med. Mater. Eng. 31, 1-17. doi: 10.3233/bme- 201076

Rashid, H. Q., Karabulut, E., and Cevik, A. (2018). Effectiveness of polypropylene mesh coated bovine amniotic membrane with adhesion barrier (polyethylene glycol) in repair of abdominal wall hernias in rats. Indian J. Anim. Sci. 88, 1010-1014.

Rauz, S., and Saw, V. P. (2010). Serum eye drops, amniotic membrane and limbal epithelial stem cells-tools in the treatment of ocular surface disease. Cell Tissue Bank. 11, 13-27. doi: 10.1007/s10561-009-9128-1

Ravi, S., and Chaikof, E. L. (2010). Biomaterials for vascular tissue engineering. Regen. Med. 5, 107-120.

Razzaghi, M., Rahavian, A., Fallah Karkan, M., Allameh, F., Ghiasy, S., and Javanmard, B. (2020). Use of human amniotic membrane repair of anterior urethral defect: first clinical report. Int. J. Urol. 27, 605-609. doi: 10.1111/iju. 14257

Rocha, S. C. M., and Baptista, C. J. M. (2015). "Biochemical properties of amniotic membrane," in Amniotic Membrane, eds A. Mamede and M. Botelho (Berlin: Springer), 19-40. doi: 10.1007/978-94-017-9975-1_2

Ryzhuk, V., Zeng, X., Wang, X., Melnychuk, V., Lankford, L., Farmer, D., et al. (2018). Human amnion extracellular matrix derived bioactive hydrogel for cell delivery and tissue engineering. Mater. Sci. Eng. C 85, 191. doi: 10.1016/j.msec. 2017.12.026

Sangwan, V. S., Burman, S., Tejwani, S., Mahesh, S. P., and Murthy, R. (2007). Amniotic membrane transplantation: a review of current indications in the management of ophthalmic disorders. Indian J. Ophthalmol. 55, 251. doi: 10.4103/0301-4738.33036

Şapte, E., Costea, C. F., Cărăuleanu, A., Dancă, C., Dumitrescu, G. F., Dimitriu, G., et al. (2017). Histological, immunohistochemical and clinical considerations on amniotic membrane transplant for ocular surface reconstruction. Roman. J. Morphol. Embryol. 58, 363-369.

Sekiyama, E., Nakamura, T., Kurihara, E., Cooper, L. J., Fullwood, N. J., Takaoka, M., et al. (2007). Novel sutureless transplantation of bioadhesive-coated, freeze-dried amniotic membrane for ocular surface reconstruction. Invest. Ophthalmol. Vis. Sci. 48, 1528-1534. doi: 10.1167/iovs.06-1104

Serna-Ojeda, J. C., García-Mejía, M., Graue-Hernández, E. O., Navas, A., and Garfias, Y. (2020). Short-term results analysis in the allogenic transplantation of limbal stem cells expanded on amniotic membrane in patients with bilateral limbal stem cell deficiency. J. Ocular Pharmacol. Ther. 36, 238-246. doi: 10. 1089/jop.2019.0147

Shabani, A., Atyabi, F., Khoshayand, M. R., Mahbod, R., Cohan, R. A., Akbarzadeh, I., et al. (2020). Design of experiment, preparation, and in vitro biological assessment of human amniotic membrane extract loaded nanoparticles. Curr. Pharm. Biotechnol. 21, 256-267. doi: 10.2174/138920102066619101912 2130

Shahriari, H. A., Tokhmehchi, F., Reza, M., and Hashemi, N. F. (2008). Comparison of the effect of amniotic membrane suspension and autologous serum on alkaline corneal epithelial wound healing in the rabbit model. Cornea 27, 1148-1150. doi: 10.1097/ico.0b013e318173138a

Shakouri-Motlagh, A., O'Connor, A. J., Kalionis, B., and Heath, D. E. (2019). Improved ex vivo expansion of mesenchymal stem cells on solubilized acellular fetal membranes. J. Biomed. Mater. Res. Part A 107, 232-242. doi: 10.1002/jbm. a. 36557

Sharifiaghdas, F., Hamzehiesfahani, N., Moghadasali, R., Ghaemimanesh, F., and Baharvand, H. (2009). Human amniotic membrane as a suitable matrix for growth of mouse urothelial cells in comparison with human peritoneal and omentum membranes. Urol. J. 4, 71-78.

Sharma, P., Kumar, P., Sharma, R., Bhatt, V. D., and Dhot, P. (2019). Tissue engineering; current status \& futuristic scope. J. Med. Life 12, 225.

Shay, E., He, H., Sakurai, S., and Tseng, S. C. G. (2011). Inhibition of angiogenesis by $\mathrm{HC} \cdot \mathrm{HA}$, a complex of hyaluronan and the heavy chain of inter- $\alpha$-inhibitor, purified from human amniotic membrane. Invest. Ophthalmol. Vis. Sci. 52, 2669-2678. doi: 10.1167/iovs.10-5888

Sheha, H., Hashemi, H., Liang, L., Ramzy, M., and ZaKi, A. (2010). Amniotic membrane extract for acute ocular chemical burns. J. Am. Sci. 6, 427-433.

Singh, R., Kumar, D., Kumar, P., and Chacharkar, M. P. (2008). Development and evaluation of silver-impregnated amniotic membrane as an antimicrobial burn dressing. J. Burn Care Res. 29, 64-72. doi: 10.1097/bcr.0b013e31815f5a0f

Sotiropoulou, P. A., Perez, S. A., Salagianni, M., Baxevanis, C. N., and Papamichail, M. (2006). Characterization of the optimal culture conditions for clinical scale production of human mesenchymal stem cells. Stem Cells 24, 462-471. doi: 10.1634/stemcells.2004-0331

Soylu, S., Yildiz, C., Bozkurt, B., Karakus, S., Kurt, B., and Kurt, A. (2018). Amniotic membrane-coated polypropylene mesh for the repair of incisional hernia: an experimental study in a rat model of abdominal wall defect. Iran. Red Crescent Med. J. 20, e62788.

Stachon, T., Bischoff, M., Seitz, B., Huber, M., Zawada, M., Langenbucher, A., et al. (2015). Growth factors and interleukins in amniotic membrane tissue homogenate. Klinische Monatsblatter fur Augenheilkunde 232, $858-862$.

Sundin, M., Ringdén, O., Sundberg, B., Nava, S., Götherström, C., and Le Blanc, K. (2007). No alloantibodies against mesenchymal stromal cells, but presence of anti-fetal calf serum antibodies, after transplantation in allogeneic hematopoietic stem cell recipients. Haematologica 92, 1208-1215. doi: 10.3324/ haematol.11446

Tabatabaei, S. A., Soleimani, M., Behrouz, M. J., Torkashvand, A., Anvari, P., and Yaseri, M. (2017). A randomized clinical trial to evaluate the usefulness of amniotic membrane transplantation in bacterial keratitis healing. Ocular Surf. 15, 218-226. doi: 10.1016/j.jtos.2017.01.004

Tandel, P. R., Surati, D., and Patel, S. R. (2018). Study of human amniotic membrane as a biological dressing in burn wounds. IJSS J. Surg. 4, 46-52.

Tauzin, H., Robin, S., Humbert, P., Viennet, C., Saas, P., Courderot-Masuyer, C., et al. (2014). Can leg ulcer fibroblasts phenotype be influenced by human amniotic membrane extract? Cell Tissue Bank. 15, 251-255. doi: 10.1007/ s10561-014-9422-4

Toniato, T. V., Stocco, T. D., Martins, D. S., Santanna, L. B., Tim, C. R., Marciano, F. R., et al. (2019). Hybrid chitosan/amniotic membrane-based hydrogels for articular cartilage tissue engineering application. Int. J. Polym. Mater. Polym. Biomater. 69, 1-10.

Torricelli, A. A. M., Santhanam, A., Wu, J., Singh, V., and Wilson, S. E. (2016). The corneal fibrosis response to epithelial-stromal injury. Exp. Eye Res. 142, 110-118. doi: 10.1016/j.exer.2014.09.012

Toyota, N., Pavcnik, D., VanAlstine, W., Uchida, B. T., Timmermans, H. A., Yin, Q., et al. (2002). Comparison of small intestinal submucosa-covered and noncovered nitinol stents in sheep iliac arteries: a pilot study. J. Vasc. Intervent. Radiol. 13, 489-498. doi: 10.1016/s1051-0443(07)61529-2

Tseng, S. C. (2016). HC-HA/PTX3 purified from amniotic membrane as novel regenerative matrix: insight into relationship between inflammation and regeneration. Invest. Ophthalmol. Vis. Sci. 57, ORSFh1-ORSFh8.

Turchan, A., Rochman, T. F., Ibrahim, A., Fauziah, D., Wahyuhadi, J., Parenrengi, M. A., et al. (2018). Duraplasty using amniotic membrane versus temporal muscle fascia: a clinical comparative study. J. Clin. Neurosci. 50, 272-276. doi: 10.1016/j.jocn.2018.01.069

Uchino, Y., Shimmura, S., Miyashita, H., Taguchi, T., Kobayashi, H., Shimazaki, J., et al. (2007). Amniotic membrane immobilized poly (vinyl alcohol) hybrid polymer as an artificial cornea scaffold that supports a stratified and differentiated corneal epithelium. J. Biomed. Mater. Res. Part B 81, 201-206. doi: 10.1002/jbm.b.30654

Vojdani, Z., Babaei, A., Vasaghi, A., Habibagahi, M., and Talaei-Khozani, T. (2016). The effect of amniotic membrane extract on umbilical cord blood mesenchymal stem cell expansion: is there any need to save the amniotic membrane besides the umbilical cord blood? Iran. J. Basic Med. Sci. 19, 89.

Washburn, S., Jennell, J. L., and Hodges, S. J. (2010). Halofuginoneand chitosan-coated amnion membranes demonstrate improved abdominal adhesion prevention. Sci. World J. 10, 2362-2366. doi: 10.1100/tsw. 2010.234

Westekemper, H., Figueiredo, F. C., Siah, W. F., Wagner, N., Steuhl, K. P., and Meller, D. (2017). Clinical outcomes of amniotic membrane transplantation in the management of acute ocular chemical injury. Br. J. Ophthalmol. 101, 103-107. doi: 10.1136/bjophthalmol-2015-308037

Xiao, X., Luo, P., Zhao, H., Chen, J., He, H., Xu, Y., et al. (2013). Amniotic membrane extract ameliorates benzalkonium chloride-induced dry eye in a murine model. Exp. Eye Res. 115, 31-40. doi: 10.1016/j.exer.2013.06.005

Yadav, M. K., Go, Y. Y., Kim, S. H., Chae, S. W., and Song, J. J. (2017). Antimicrobial and antibiofilm effects of human amniotic/chorionic membrane extract on streptococcus pneumoniae. Front. Microbiol. 8:1948. doi: 10.3389/fmicb.2017. 01948

Yang, Y., Zhang, Y., Yan, Y., Ji, Q., Dai, Y., Jin, S., et al. (2020). A Sponge-like double-layer wound dressing with chitosan and decellularized bovine amniotic 
membrane for promoting diabetic wound healing. Polymers 12, 535. doi: 10. 3390/polym12030535

Zhang, Q., Qian, C., Xiao, W., Zhu, H., Guo, J., Ge, Z., et al. (2019). Development of a visible light, cross-linked GelMA hydrogel containing decellularized human amniotic particles as a soft tissue replacement for oral mucosa repair. RSC Adv. 9, 18344-18352. doi: 10.1039/c9ra03009c

Zhou, Z., Long, D., Hsu, C. C., Liu, H., Chen, L., Slavin, B., et al. (2019). Nanofiber-reinforced decellularized amniotic membrane improves limbal stem cell transplantation in a rabbit model of corneal epithelial defect. Acta Biomater. 97, 310-320. doi: 10.1016/j.actbio.2019. 08.027
Conflict of Interest: The authors declare that the research was conducted in the absence of any commercial or financial relationships that could be construed as a potential conflict of interest.

Copyright (c) 2021 Dadkhah Tehrani, Firouzeh, Shabani and Shabani. This is an open-access article distributed under the terms of the Creative Commons Attribution License (CC BY). The use, distribution or reproduction in other forums is permitted, provided the original author(s) and the copyright owner(s) are credited and that the original publication in this journal is cited, in accordance with accepted academic practice. No use, distribution or reproduction is permitted which does not comply with these terms. 